\title{
Bitter crab disease: a fatal dinoflagellate infection and marketing problem for Alaskan Tanner crabs Chionoecetes bairdi
}

\author{
Theodore R. Meyers ${ }^{1}$, Timothy M. Koeneman ${ }^{2}$, Catherine Botelho ${ }^{2}$, Sally Short ${ }^{1}$ \\ ${ }^{1}$ Division of Fisheries Rehabilitation, Enhancement and Development (FRED), Alaska Department of Fish and Game, \\ PO Box 3-2000, Juneau, Alaska 99802-2000, USA \\ ${ }^{2}$ Division of Commercial Fisheries, Alaska Department of Fish and Game
}

\begin{abstract}
A systemic dinoflagellate disease was discovered in Tanner crabs Chionoecetes bairdi harvested from two-thirds of the major production areas in the northern southeast panhandle of Alaska during 1985 and 1986. Processed meats from infected crabs were unmarketable as a result of a bitter flavor imparted by the causative agent. The disease is chronic but lethal, causing $100 \%$ mortality in naturally infected crabs when maintained in flowing seawater during a 5 mo period. Feral Tanner crabs in at least one harvest area had a parasite prevalence of $95 \%$ regardless of sex or age class. Disease pathogenesis and parasite description, probable life history, distribution and management implications are discussed.
\end{abstract}

\section{INTRODUCTION}

The Tanner crab Chionoecetes bairdi, marketed as snow crab, has been an economically important target species for commercial fishermen in southeastern Alaska for several years. The average annual catch of Tanner crab harvested in southeast Alaska for the last 3 yx (1984-1986) has been 1.2 million lbs (ca 545 t) with an ex-vessel value of US $\$ 2.3$ million. In 1985, during February through April, 4 lots of Tanner crabs (about 66000 lbs [30 t] live $w t)$ purchased by a local southeastern Alaska processor contained crab meats having a markedly bitter aftertaste. During this same period in 1986 more than 80282 lbs (36.4 t) of live crabs purchased by the same company were unmarketable due to the same bitter flavor. Also in 1986, a second local processor had similar problems with bitter crabs. Approximately 29567 lbs (13.4 t) of live crabs were not marketable and represented $11.4 \%$ of the Tanner crabs delivered to this second facility from 24 February through 29 March. This loss is conservative because crab deliveries prior to discovery of the problem on 24 February are not included and not all processors had provided adequate catch information. Before the closing of the 1986 Tanner crab season, commercial fishermen were able to recognize affected live crabs by a pink carapace and milky hemolymph. Such crabs were being culled from their harvests on the fishing grounds and at the processors' docks. By grading bitter crabs from tender purchases on the fishing grounds, the latter processing company was able to reduce overall seasonal losses to $7.7 \%$. A conservative estimate of dollars lost from unmarketable bitter Tanner crabs for both companies was over US \$175758 in 1986.

A laboratory examination of these crabs showed them to be infected with a non-motile single-celled protistan blood parasite resembling Hematodinium sp. reported in other decapod crustacean hosts. Chatton \& Poisson (1931) originally described H. perezi in the hemolymph of Carcinus maenas and Portunus depurator from European waters. Years later the parasite was found in the blue crab Callinectes sapidus from the southeastern United States (Newman \& Johnson 1975), in 2 species of cancer crabs, Cancer irroratus and $C$. borealis, and in another portunid, Ovalipes oscellatus, from the mid-Atlantic Bight (MacLean \& 
Ruddell 1978). Most recently, dinoflagellates resembling Hematodinium have been described as parasites of benthic amphipods (Johnson 1986).

We believe this dinoflagellate parasite is responsible for the bitter off-flavor occurring in cooked Tanner crabs and consequently is economically significant to the seafood industry. The purpose of this report is to provide new information regarding: gross and microscopic descriptions of bitter crab disease; disease pathogenesis in Tanner crabs; ultrastructural morphology of the causative agent; transmissibility of the agent in Tanner and king crab species and its in vitro culture characteristics; prevalence and distribution of the disease in Alaskan Tanner crabs based on current catch information.

\section{MATERIAL AND METHODS}

Necropsy and histopathology. Necropsies performed on pink or milky crabs provided representative tissue samples from the major organ systems. These were preserved in Helley's fixative $\left(\mathrm{ZnCl}_{2}\right.$ substituted for $\mathrm{HgCl}_{2}$ ) for standard histological processing and staining with hematoxylin and eosin (H\&E). Hemolymph for smears was drawn in ml syringes from the third joint of the right cheliped of each crab. Resulting films on glass slides were fixed and stained using the Diff-Quik method (Dade Diagnostics, Inc. Aguada, Puerto Rico 00602). Entire hemolymph films were examined at $100 \times$ magnification (approximately 264 fields) for diagnosis of infection. Wet hemolymph smears containing live parasites were examined with bright field and phase contrast microscopy. Measurements of organisms were made from both fresh and histological preparations at $400 \times$ using an ocular micrometer.

Disease pathogenesis. Host mortality and parasite development were examined in the following way. Infected and apparently uninfected crabs sorted by a seafood processor were brought into the laboratory, tagged for identification and maintained in separate $100 \mathrm{gal}$ (ca $380 \mathrm{l}$ ) rectangular fiberglass tanks supplied with running seawater at approximately $3 \mathrm{gpm}$ (ca 11 I $\min ^{-1}$ ) with salinities of 28 to $32 \mathrm{ppt}$. Both groups were re-sorted according to the presence or absence of the parasite in hemolymph smears. The accuracy of external disease signs used by fishermen and processors to identify infected crabs was evaluated by diagnosis with hemolymph smears. Both groups of crabs were fed herring ad libidum and held for an extended period of time to allow for disease progression in infected crabs and cumulative mortality. Hemolymph films from surviving crabs were made at the end of the experiment to confirm the infected and control status of both crab groups. Saltwater temperatures were monitored 3 to 4 times a week beginning 1 mo after the start of the mortality study

Electron microscopy. About 0.5 to $1.0 \mathrm{ml}$ of hemolymph or sterile seawater containing parasite vegetative stages from $2 \mathrm{crabs}$ and dinospores from 2 others were preserved in $4 \%$ glutaraldehyde in seawater at $4{ }^{\circ} \mathrm{C}$ for $24 \mathrm{~h}$. The samples were post-fixed in $1 \%$ osmium tetroxide in $0.1 \mathrm{~m}$ cacodylate buffer $(\mathrm{pH}$ 7.2 ) and placed in $70 \% \mathrm{EtOH}$ for storage. Aliquots of fixed organisms were processed for standard transmission electron microscopy (TEM) using Spurr's resin or Quetol 651 for embedding and uranyl acetate and lead citrate stains. Thin sections were examined in a Philips 200 or 300 TEM operated at 40 and $60 \mathrm{kV}$, respectively. The remainder of the samples in alcohol were filtered onto a $13 \mathrm{~mm}$ nucleopore polycarbonate membrane, critically point dried in trichlorotrifluoroethane, coated with gold palladium and examined in an AMRAY 1000-A scanning electron microscope (SEM) at $20 \mathrm{kV}$.

Disease transmission studies. Two control crabs from the pathogenesis study received 0.1 and $1.0 \mathrm{ml}$ inoculations, respectively, of hemolymph freshly drawn from one of the infected crabs (No. 9). Two additional uninfected controls were inoculated with 0.2 and $2.0 \mathrm{ml}$, respectively, of a suspended subculture of the dinoflagellate organism which had been maintained in the laboratory for $70 \mathrm{~d}$ after isolation from another of the infected crabs (No. 5). Approximate hemocytometer counts of organisms in the preparations used for inocula were $5.01 \times 10^{5}$ cells $\mathrm{ml}^{-1}$ and $5.56 \times 10^{5}$ cells $\mathrm{ml}^{-1}$ for freshly drawn hemolymph and cultured material, respectively. These 4 crabs were maintained in a separate tank of flowing seawater and were bled periodically to determine if a clinical infection had developed. Inoculations were made in the right cheliped of each crab but subsequent bleedings were done from the left cheliped. The remaining 5 control crabs were maintained in another saltwater tank.

Results from the 4 Tanner crabs allowed the design. of a second experiment testing the susceptibility of another commercially important crab species to infection with the vegetative stage of the Tanner crab dinoflagellate. Five female red king crabs Paralithodes camtschatica were each inoculated with $1 \mathrm{ml}$ of pooled hemolymph from 3 naturally infected male Tanner crabs. Six unparasitized male Tanner crabs were also inoculated in the same manner and served as positive controls. The inoculum for both crab species contained dinoflagellate vegetative stages averaging $5.34 \times 10^{6}$ cells $\mathrm{ml}^{-1}$. Another 5 red king and 5 Tanner crabs served as sham inoculated controls each receiving $1 \mathrm{ml}$ of hemolymph pooled from 6 normal Tanner crabs. Inoculations, periodic bleedings and maintenance of crabs in flowing seawater were as explained above 
with sham inoculated crabs kept in a separate tank. The king crabs were collected locally from Auke Bay while Tanner crabs were purchased from commercial fishermen. Hemolymph from all inoculated crabs was examined prior to the experiment to confirm that animals were not infected with the dinoflagellate.

In vitro culture. Clotted hemolymph from 3 uninfected control crabs was centrifuged at $1500 \mathrm{~g}$ for 10 min. The supernatant fluid was sterilized through a $0.45 \mu \mathrm{m}$ filter only after difficult prefiltration through a $0.5 \mu \mathrm{m}$ filter. Approximately $1 \mathrm{ml}$ of hemolymph from a crab severely infected with the vegetative stages of the organism was collected aseptically in a sterile syringe after surface disinfection with an iodophor solution. The organism was pelleted at $1500 \mathrm{~g}$ for $5 \mathrm{~min}$ and resuspended in $6 \mathrm{ml}$ of filtered hemolymph. Three $\mathrm{ml}$ of this suspension were pipetted into an up-ended $25 \mathrm{~cm}^{2}$ plastic tissue culture flask. The remaining $3 \mathrm{ml}$ were placed in a similar flask containing a mixture of penicillin, streptomycin and amphotericin $B$ at final concentrations of $100 \mathrm{IU} \mathrm{ml}^{-1}, 100 \mu \mathrm{g} \mathrm{m}^{-1}$ and $0.25 \mu \mathrm{g}$ $\mathrm{ml}^{-1}$, respectively. Resistance of the organism to this cocktail permitted subsequent subculturing using unfiltered aseptically collected hemolymph containing the antibiotic mixture. Hemolymph cultures were incubated at 4 to $6^{\circ} \mathrm{C}$

Dinospore stages of the organism were maintained in a similar manner, but also in sterile seawater containing the same antibiotic mixture.

Prevalence and distribution. Distribution of the disease and resultant commercial losses of product were ascertained from landing information provided by 2 southeast Alaska processors. Affected crabs were recognized by visual inspection of cooked and uncooked carcasses and taste testing of the final product. Fishermen provided additional distributional information, but both sources of data related specifically to male legalsized crabs $\geq 140 \mathrm{~mm}$ in carapace width. Infection prevalences between crab sexes and among different size classes were ascertained by the Alaska Department of Fish and Game (ADF\&G), Commercial Fisheries Division, using a systematic pot survey in a $1 / 3$ nautical mile grid pattern within a harvest area reported by fishermen to have had a high prevalence of diseased crabs. Twenty $2 \times 2 \mathrm{~m}$ commercial king crab pots webbed with 3.5 inch (ca $9 \mathrm{~cm}$ ) stretch measure mesh were baited with herring and set at depths ranging from 15 to 60 fathoms (ca 27 to $110 \mathrm{~m}$ ) with soak times of approximately 15 to $22 \mathrm{~h}$. The same grid area was sampled again the following year by ADF\&G using a $40 \mathrm{ft}(12 \mathrm{~m})$ beam trawl designed for capturing pink shrimp. Bottom times for the trawl ranged between 20 to $60 \mathrm{~min}$ at a speed of 1.5 knots. Hemolymph smears from randomly caught Tanner crabs were made and examined in the manner previously described.

\section{RESULTS}

\section{Description of disease and agent}

\section{Gross appearance}

Commercial seafood processors detected a bitter aspirin-like aftertaste, medicinal odor and chalky texture that varied by degrees in certain lots of their cooked Tanner crab meats. Quality-control records indicated that fresh meats from condemned lots were abnormally opaque, odorless and soft with an oozing milky fluid. Adherent epidermis was a brilliant orange, but the pigment was unstable and easily transferred into the curd after cooking. Later in the season some commercial fishermen, alerted to this condition, were able to cull many affected crabs in the field. Such crabs were recognized by a peculiar pinkish carapace and a dirty white line appearing on the length of the ventral shell of the merus leg segments. In questionable crabs, one of the rear walking legs would be removed to observe for a milky fluid. Infected crabs also appeared more lethargic and died more readily from handling stress on the tender boats than did uninfected crabs.

Necropsies of 11 potentially infected crabs were performed in the fish disease laboratory at the University of Alaska, Juneau. These crabs had been sorted by processors using the criteria above. Eight of these crabs had varying degrees of epidermal hyperpigmentation and opalescent white hemolymph upon removal of the dorsal carapace. The internal organs of these crabs appeared 'frosted' with a friable white residue. Body and leg musculature was atrophied, soft and opaque with cloudy white hemolymph exuding from the cut surfaces. The 3 remaining crabs were normal on internal examination.

\section{Microscopic appearance}

Fixed and stained hemolymph films from the 8 milky crabs and 1 of the apparently normal crabs showed varying intensities of a round to oval unicellular organism present as single cells, as multinucleated aggregates and as binucleated forms in probable late cell division. Cell nuclei were deep purple, eccentric, had indistinct margins with no visible nucleoli and frequently exhibited the dinokaryon-type morphology described for Hematodinium (Chatton \& Poisson 1931). The cell cytoplasm was non-staining, very vesicular, sometimes having a thin amorphous border with protruding or externally attached spherical droplets (Fig. 1). Circulating host hemocytes, although usually in considerable minority to the parasite, were frequent in living crabs. Impression smears of internal organs also demonstrated myriads of similar organisms. 


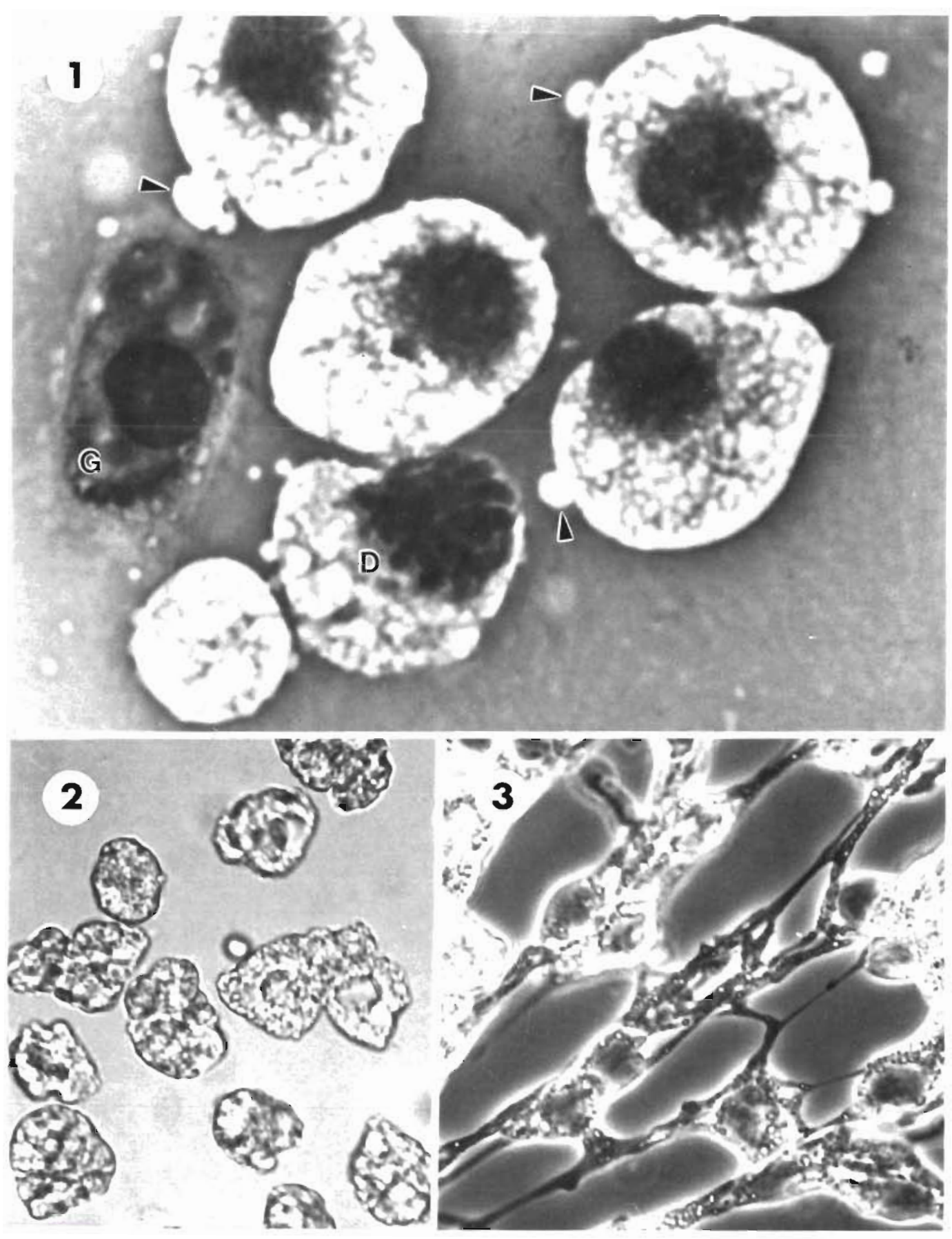

Figs. 1 to 3. Chionoecetes bairdi. Fig. 1. Fixed hemolymph smear from an infected crab showing dinoflagellate vegetative stages and a host granulocyte (G); note dinokaryon-type nuclear division (D) and droplet formation (arrows) on external surface of nonstaining pellicle $e_{i}$ Diff-Quik. $\times 5000$. Fig. 2. Wet hemolymph smear of living dinoflagellate vegetative stages from an infected crab; note irregular shapes and variable size $\times$ $\times 2000$. Fig. 3 . Attached dinoflagellate vegetative stages $29 \mathrm{~d}$ in hemolymph culture after collection from an infected crab; $\times 2000$

Wet mounts of fresh hemolymph from infected crabs clearly demonstrated an irregular surface of the parasite cells, their non-motility and the thin clear cytoplasmic border observed in stained smears. Parasite cell cytoplasm was filled with several distinct round inclu- sion bodies, probably responsible for the vesicular staining of the cells. Also, occasional parasite cells had 1 to 3 slowly undulating filament-like structures of varying lengths which did not rotate on an axis and, consequently, did not resemble flagella (Figs. 2 and 4). 
Cell dimensions of individual living organisms were variable ranging from $17.1 \times 26.6 \mu \mathrm{m}$ to $9.5 \mu \mathrm{m}$ in diameter $(n=12)$. Average dimensions of 8 randomly chosen parasite cells were $15.4 \times 20.7 \mu \mathrm{m}$. Cell nuclei were consistently $7.6 \mu \mathrm{m}$ in diameter $(\mathrm{n}=12)$.
Histological sections from the same 9 crabs having infected hemolymph also demonstrated similar but variably sized unicellular organisms in blood sinuses and tissues. Fixed cells in paraffin sections averaged $15.6 \times$ $12.8 \mu \mathrm{m}(\mathrm{n}=8)$ with a nucleus of $6.2 \mu \mathrm{m}(\mathrm{n}=6)$ in
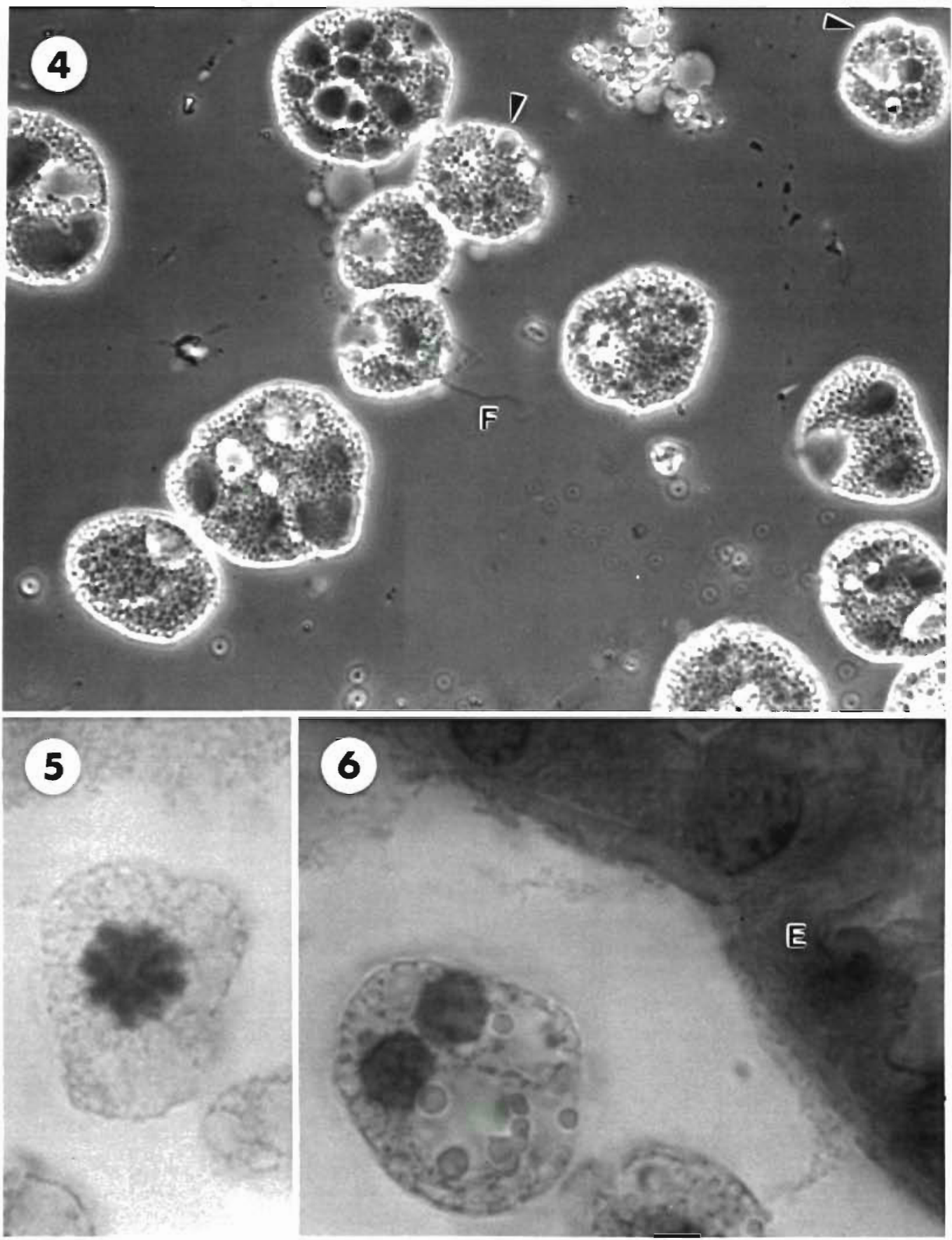

Figs. 4 to 6. Chionecetes bairdi. Fig. 4. Wet hemolymph smear of living dinoflagellate vegetative stages from an infected crab which have been compressed by the coverslip; note streaming filamentous structure $(F)$ and numerous cytoplasmic inclusions some of which cause outward bulging (arrows) of the thick refractile pellicle; phase contrast; $\times 2000$. Fig. 5 . Dinokaryon nuclear division of a dinoflagellate vegetative stage in infected crab tissues showing $V$-shape pairs of chromosomes; hematoxylin and eosin; $\times 5000$. Fig. 6 . Binucleated dinoflagellate vegetative stage within the lumen of the labyrinth portion (E) of the antennal gland from an infected crab; hematoxylin and eosin; $\times 5000$ 
diameter (Figs. 5 and 6). Eight of the crabs were severely infected with the organism throughout all tissues where hemolymph is normally found. The 9th crab, which had 2 to 3 organisms in a hemolymph smear, had a single small focus of organisms in the connective tissue of the pyloric stomach. The primary histopathology caused by this parasite was replacement of vascularized tissues throughout the body, mostly connective tissues, and severe congestion of hemal spaces. The organism was most numerous in the vesicular connective tissues of: the epidermis; the pyloric stomach directly beneath the mucosa; the hepatopancreas interstitially among the tubular elements; the intestinal tract, especially outside of the circular muscular layer. Glial elements surrounding the optic ganglia of the eyestalk were also severely infiltrated by this organism. The major hemal spaces most congested with this organism included: the trabecular channels within the myocardium; the branchial sinuses within the gill filaments (Fig. 7); the sinuses of the eyestalks beneath the omatidia and surrounding the primary optic nerve fibers; the sinus in the coelomosac of the antennal gland with replacement of podocytes and some but fewer organisms visible in the lumen of the labyrinth. Actual cellular damage associated with this organism was not extensive but included: muscle cell degeneration (loss of cytoplasmic eosinophilia and striations) and necrosis in visceral organs and body musculature; epithelial necrosis and cell degeneration in hepatopancreatic tubules characterized by increased vacuolation, basophilic granularity of cell cytoplasm, pale nuclei (Fig. 8) and occasional organisms in the tubule lumina; necrosis and ulceration of epidermal epithelium beneath the carapace with myriads of organisms forming an exudate on the tissue surface (Fig. 9); occasional pyknosis of urinary bladder epithelium and presence of organisms within the bladder lumen. A host cell response to invasion by this organism was absent in most tissues. Occasional large foci of mostly agranular hemocytes and some eosinophilic granulocytes were observed in the coelomosac of the antennal gland and in the surrounding connective tissues of the urinary bladder in infected crabs.

\section{Disease pathogenesis}

Hemolymph smears from 20 male Tanner crabs correlated closely with previous sorting by processors into infected and uninfected groups of 10 each. However, recognition of diseased crabs by external clinical signs did produce a $10 \%$ error (1 uninfected crab) in the infected group and a $20 \%$ error ( 2 infected crabs) in the uninfected group. After re-sorting crabs by hemolymph smears infected and uninfected groups were comprised of 11 and 9 crabs, respectively. Mean live weights $(\mathrm{g})$ for control and infected crabs were $1263 \pm 305$ and $1334 \pm 182$, respectively. Mean carapace widths (mm) were $153 \pm 13$ and $161 \pm 12$, respectively. The majority of these crabs had 'new shells' excepting 3 and 1 old shell crabs in the control and infected groups, respectively. During $97 \mathrm{~d}$ of observation $67 \%$ (7) of the infected crabs died while no losses occurred in the uninfected group. At this time initiation of a disease transmission study described below required use of 4

Table 1. Chionoecetes bairdi. Survival of 11 Tanner crabs naturally infected with a parasitic dinoflagellate during $158 \mathrm{~d}$ from 28 March to 2 September $1986^{\circ}$

\begin{tabular}{|c|c|c|c|c|c|}
\hline Crab No. & $\begin{array}{c}\text { Approx. } \\
\text { water temp }\left({ }^{\circ} \mathrm{C}\right)^{\mathrm{b}}\end{array}$ & $\begin{array}{l}\text { Survival } \\
\text { (d) }\end{array}$ & $\begin{array}{l}\text { Moribund (M) } \\
\text { or dead (D) }\end{array}$ & $\begin{array}{l}\text { Secondary hemo- } \\
\text { lymph infection }\end{array}$ & $\begin{array}{c}\text { Dinoflagellate } \\
\text { life stage }\end{array}$ \\
\hline 3 & 3.8 & 20 & $\mathrm{D}$ & Bacteria & Vegetative \\
\hline 13 & - & 33 & D & Bacteria \& ciliate & Vegetative \\
\hline 2 & 5.2 & 58 & D & $N^{c}$ & $\mathrm{NE}$ \\
\hline 5 & 5.2 & 58 & $\mathrm{D}$ & $\mathrm{NE}$ & NE \\
\hline 7 & 5.2 & 58 & M & Bacteria & Vegetative \\
\hline 1 & 6.0 & 75 & $\mathrm{D}$ & Ciliate & Vegetative \\
\hline 10 & 6.5 & 90 & $\mathrm{D}$ & Bacteria & Vegetative \\
\hline 6 & 7.4 & 123 & $M$ & None & Vegetative \\
\hline 12 & 7.8 & 140 & $\mathrm{D}$ & Bacteria \& ciliate & Prespore \\
\hline 4 & 8.6 & 149 & $D^{d}$ & Bacteria & Dinospore \\
\hline 9 & 7.7 & 158 & $D^{e}$ & None & Dinospore \\
\hline \multicolumn{6}{|c|}{$\begin{array}{l}\text { No mortalities in uninfected control crabs } \\
\text { b Seawater temperatures recorded every other day beginning } 40 \mathrm{~d} \text { into the experiment. Some readings are averages rather } \\
\text { than actual observations for a given day } \\
{ }^{c} \mathrm{NE}=\text { not examined because of severe post-mortem change } \\
\text { d Blood smear examined } 2 \mathrm{~d} \text { prior to death } \\
\text { e Blood smear examined } 1 \mathrm{~d} \text { prior to death. Prespore stages were first observed } 10 \mathrm{~d} \text { prior to death }\end{array}$} \\
\hline
\end{tabular}



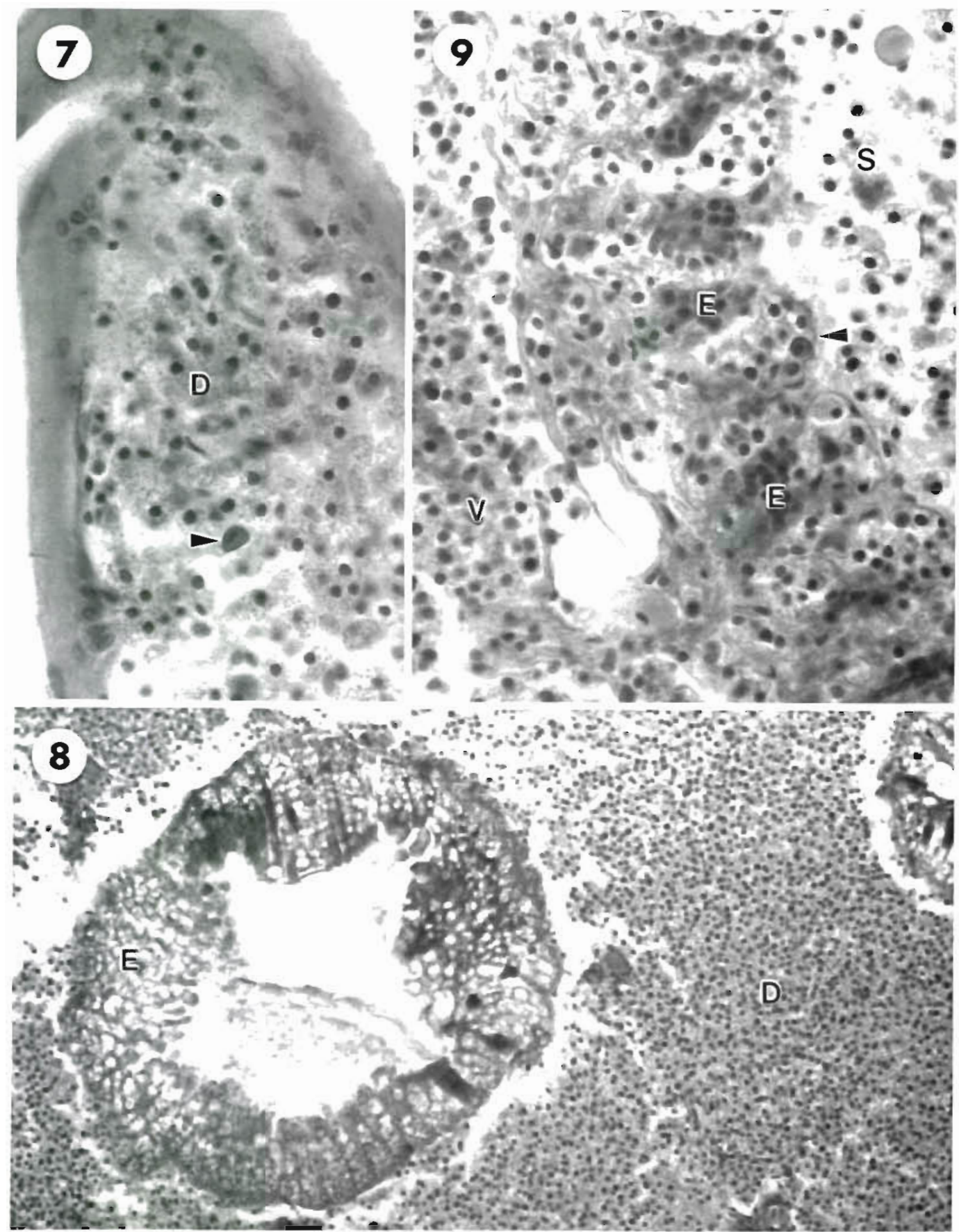

Figs. 7 to 9. Chinoecetes bairdi. Fig. 7. Gill filament from an infected crab showing engorgement of vascular spaces with dinoflagellate vegetative stages $(\mathrm{D})$; host granulocyte (arrow); hematoxylin and eosin; $\times 800$. Fig. 8 . Hepatopancreas from an infected crab with vacuolar degeneration and loss of nuclear staining in tubular epithelium (E) and replacement of interstitial vesicular connective tissue by myriads of dinoflagellate vegetative stages (D); hematoxylin and eosin; $\times 315$. Fig. 9. Epidermal border beneath carapace of an infected crab showing a basement membrane (arrow) devoid of an epithelial border except for remnant nests of cells $(E)$ in tissue folds; myriads of dinoflagellate vegetative stages replace vesicular connective tissue of the visceral side ( $V$ ) of the epidermis and have infiltrated to the epidermal surface (S) forming part of an exudate; hematoxylin and $\operatorname{eosin} ; \times 800$

control crabs leaving 5 uninfected crabs for the remainder of the pathogenesis study. By Day 158 all naturally infected crabs were dead. No deaths had yet occurred in the control crab group (Table 1). Hemolymph from all of the infected crabs, except one, was severely infected with the organism when initially examined. The infected crab with relatively fewer organisms in peripheral circulation was one of the last to die at $140 \mathrm{~d}$ 

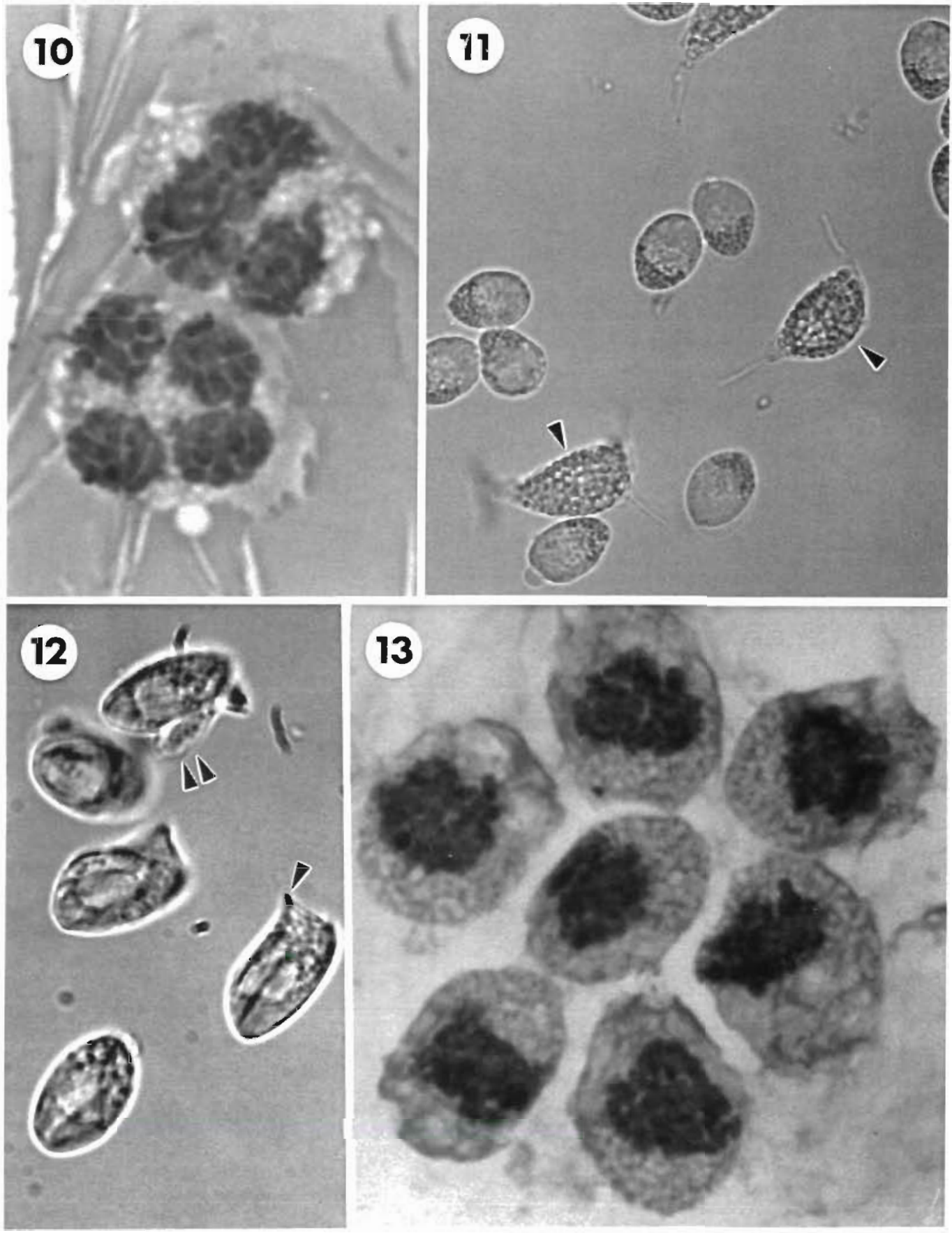

Figs 10 to 13 Spores of dinoflagellate Fig 10 Fixed crab hemolymph smear of dinoflagellate multinucleated prespore stages undergoing rapid cell division, cells taken from infected Tanner crab No 9.9 a prior to sporulation into the smaller type of dinospore (Figs $14 \& 15$ ). Diff-Quik. $\times 5000$ Fig 11 Wet crab hemolymph smear of live dinospores of the larger type 24 h after collection from infected Tanner crab No. 4 (slight lateral protrusion not shown), host granulocytes (arrows); $\times 2000$. Fig. 12. Live dinospores in Fig 11 after $11 \mathrm{~d}$ in hemolymph (ulture showing development of distinct lateral keel (double arrow) and beaked end (single arrow), $\times 3300$ Fig. 13. Fixed hemolymph smear of 24 h-old large type dinospores in Fig. 11 showing lobed nuclei with distinct outlines not apparent in vegetatıve stages lllustrated in Fig 1; Diff-Quick; $\times 5000$ 
Figs. $14 \& 15$. Spores of dinoflagellate. Fig. 14 . Wet smear of live dinospores of the smaller type $2 \mathrm{~d}$ in saltwater culture after collection from infected Tanner crab No. 9. Note refractile granule (arrow) at distal posterior end; $x$ 3300; inset: same dinospore type in a fixed smear after $11 \mathrm{~d}$ in saltwater culture showing a bent profile, densely staining spore body and 2 flagella; Diff-Quick; $\times 4000$. Fig. 15. Glutaraldehyde fixed dinospores from Fig. 14 after 11 $d$ in saltwater culture demonstrating pronounced corkscrew shape and 2 obvious flagella; phase contrast; $\times 1320$
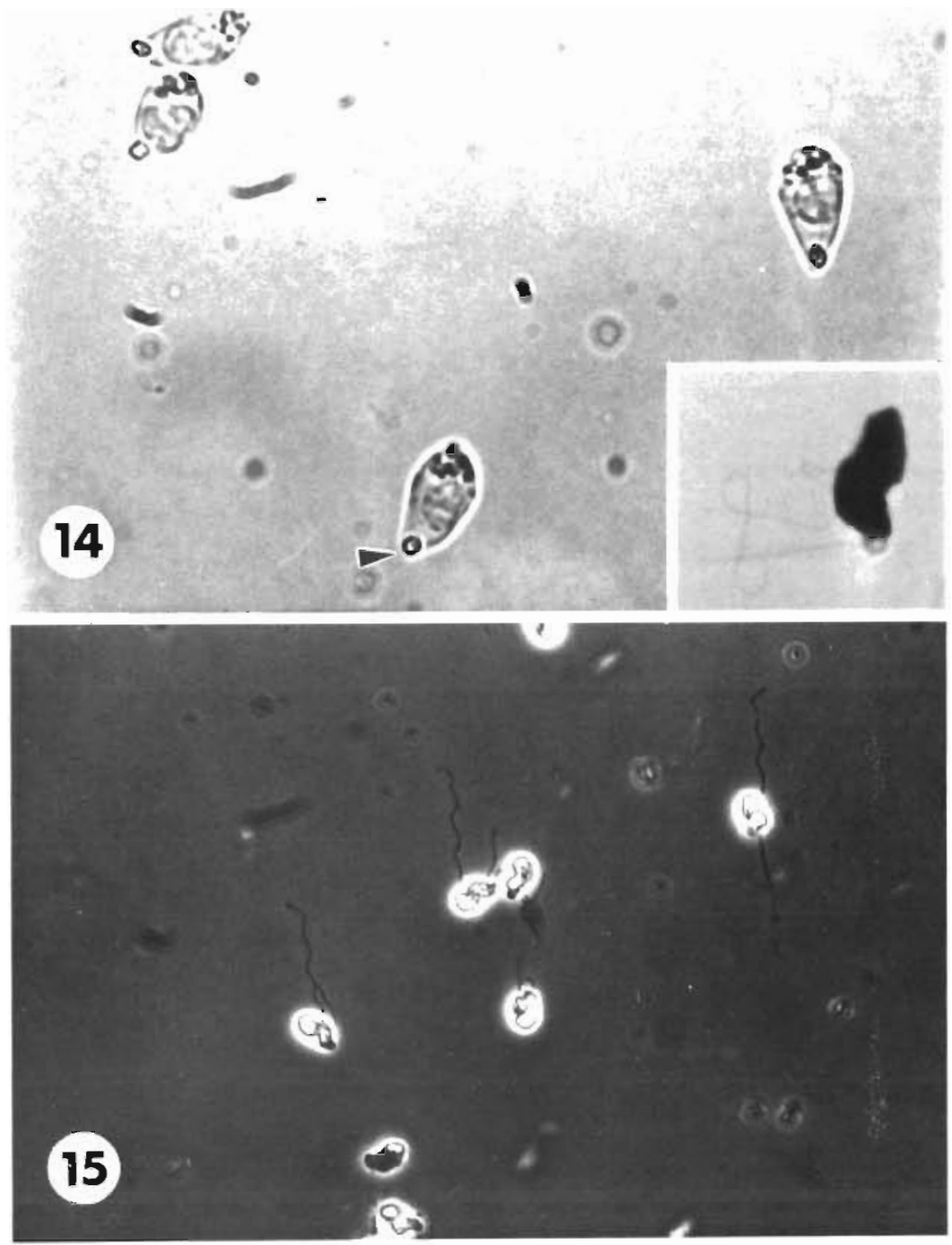

(Table 1). The clotting characteristics of infected crab hemolymph were indistinguishable from those of control crabs. Most of the crab mortalities occurred suddenly with little behavioral changes except chronic anorexia and progressive lethargy. Crabs were considered moribund when movements of antennae and/or mouth parts were still discernible but the animals were unable to right themselves when turned over or failed to move when prodded.

Seawater temperatures ranged from $3.8^{\circ} \mathrm{C}$ early in the mortality study to $8.9^{\circ} \mathrm{C}$ near the end of the study. Respective average seawater temperatures $\left({ }^{\circ} \mathrm{C}\right)$ for May, June, July, August and September were: 4.6 $(n=15), 5.6(n=18), 7.0(n=14), 7.8(n=12), 7.0 \quad(n=6)$.

Hemolymph smears from 5 of the dead infected crabs showed assorted bacterial rods in 4 individuals and an unidentified ciliate in 3 , in addition to the dinoflagellate organism (Table 1). Infected hemolymph from 2 of 4 additional crabs, one moribund and the other taken $2 \mathrm{~d}$ prior to death, also contained obvious bacterial rods. Histological examination of one of the moribund crabs showed overwhelming numbers of the dinoflagellate cells in the tissues and tissue pathology similar to that described. Hemolymph from the control crabs remained free of any detectable infectious agents throughout the observation period.

Hemolymph smears from the last 3 surviving infected crabs in the experiment exhibited dinoflagellate cells quite different in appearance than previously noted. Multinucleated forms were present in the dead crab No, 12 (Table 1) as were single-celled stages which were much smaller than the previous larger vegetative forms. Parasite nuclei had markedly beaded chromatin and were lobed with uncharacteristic distinct outlines. Similar prespore stages were observed in crab No. 9 ten d prior to death (Fig. 10). One d prior to death these stages were completely 


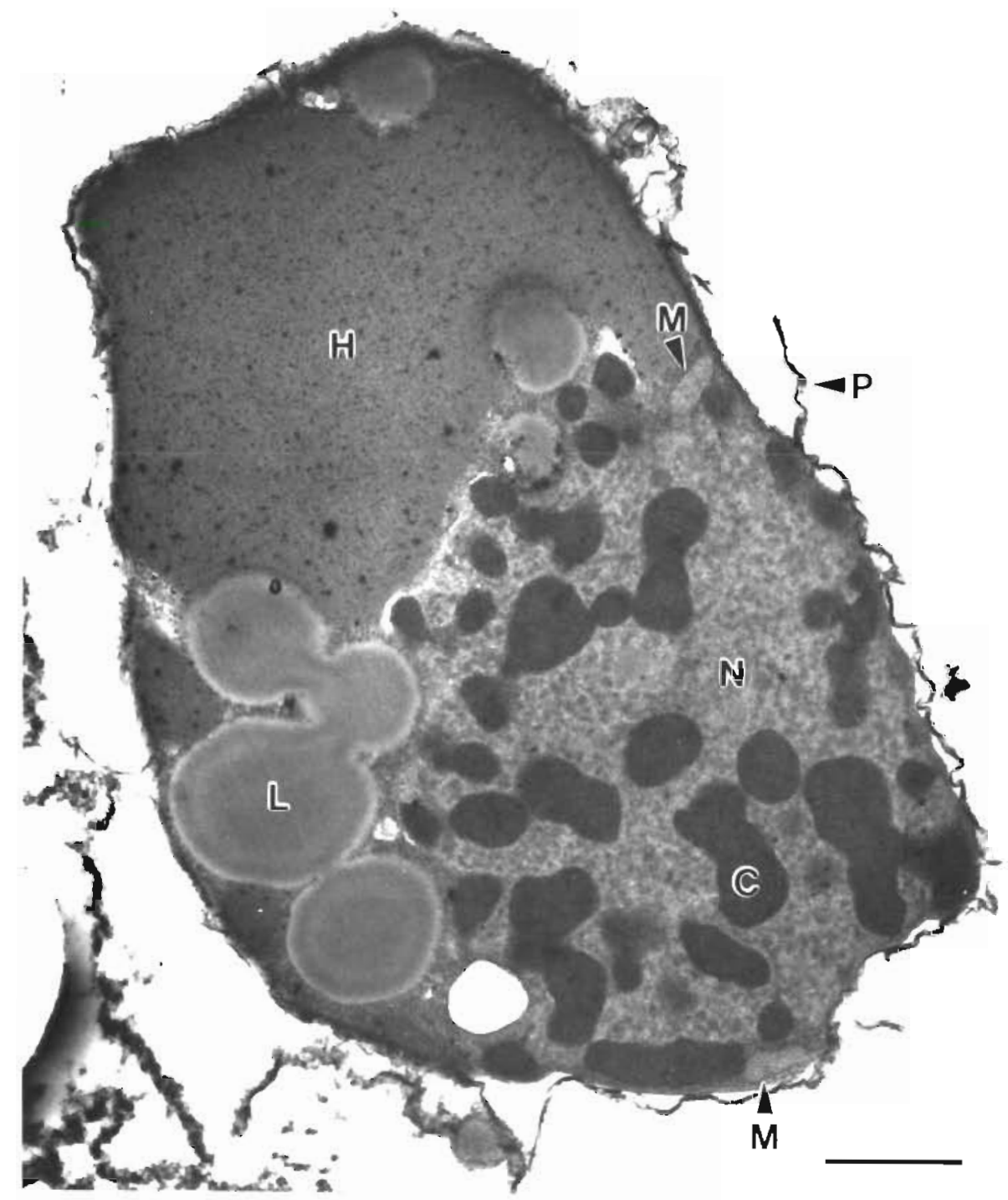

Fig. 16. Typical dinoflagellate vegetative stage from the hemolymph of an infected Tanner crab. Transmission electron micrograph. Nucleoplasm (N) with beaded chromatin clumps (C), cytoplasmic membrane-bound homogenous granular substance $(\mathrm{H})$ associated with large vacuoles containing a lipid-like material (L), mitochondria (M) in thin strands of compressed cytoplasm, and irregular electron dense pellicle (P) showing separation of layers. Uranyl acetate-lead citrate: $x$ 17620 ; bar $=1 \mu \mathrm{m}$ sporulated into a single type of biflagellated dinospore with very rapid spiral motility Crab No. 4 also developed a distinct dinospore stage within the hemolymph $2 \mathrm{~d}$ prior to death. Sporulated hemolymph in both crabs was opaque and white with spore concentrations in crab No. 4 estimated at $3.67 \times 10^{7} \mathrm{ml}^{-1}$ of hemolymph. Despite identical appearing vegetative stages, the dinospores from one crab differed from those of the other in size, morphology and behavior. Both spore types underwent morphological changes during maintenance in hemolymph and saltwater cultures. Dinospores from crab No. 4 were oval, about $15.2 \times 11.4 \mu \mathrm{m}(\mathrm{n}=8)$, with a slight lateral protrusion when first extracted from the host (Fig. 11). After $9 \mathrm{~d}$ in hemolymph culture the lateral protrusion developed markedly into a keel-like structure with a beak-like protrusion at one end (Fig. 12). In stained smears these spores resembled smaller vegetative stages; flagella were not visible but nuclei were longer than wide, lobed and distinct in outline (Fig. 13). Their general measurements remained the same. Dinospores from crab No. 9 were more elliptical with narrower and shorter dimensions $(12.0 \times 4.4 \mu \mathrm{m} ; \mathrm{n}=5)$ with a slight lateral ridge (Fig. 14). After $24 \mathrm{~h}$ in saltwater culture these spores developed a bent corkscrew shape that was more pronounced $6 \mathrm{~d}$ later (Fig. 15). A distinct feature of this spore was a refractile round body located distally at the posterior end (Fig. 14). In stained smears the refractile body and 2 flagella were obvious as was a dense overall staining of the spore body (Fig. 14). These dinospores moved much more rapidly and erratically than the larger dinospores from crab No. 4. 

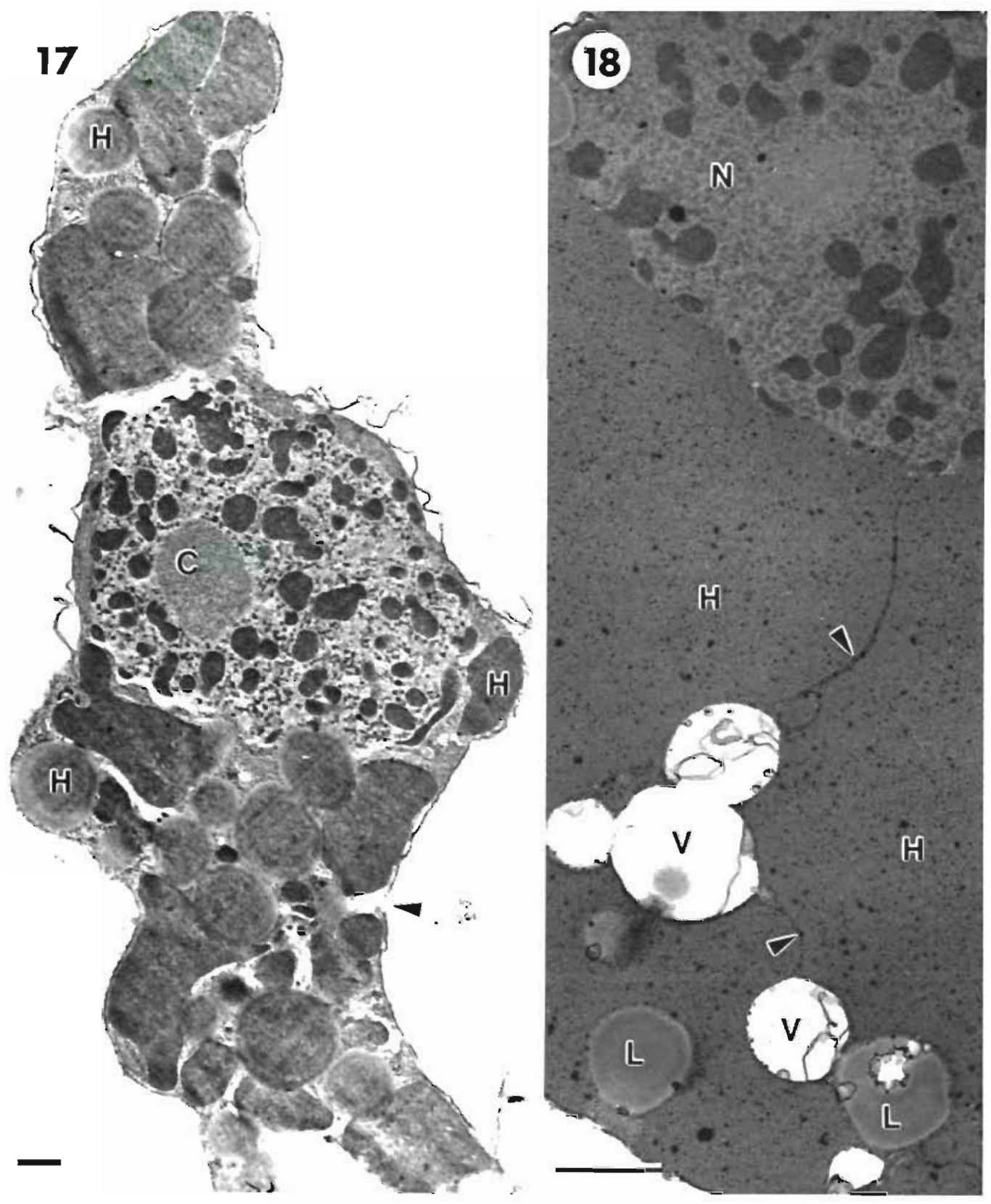

Figs. $17 \& 18$. Vegetative dinoflagellate cell. Fig. 17. Ultrastructure showing cytoplasmic invagination (C) in the nucleus, and numerous granular cytoplasmic inclusions $(\mathrm{H})$ some of which cause outward bulging of the pellicle; a break within the pellicle integrity is visible (arrow); uranyl acetate-lead citrate; $\times 7000$; bar $=1 \mathrm{um}$. Fig. 18 . Detail of cell showing empty vacuoles (V) containing membranous debris and others filled with a lipid-like material $(\mathrm{L})$; these vacuoles are within enlarged areas of cytoplasm which is usually compressed as thin strands (arrows) between voluminous homogenous granular inclusion bodies (H); nucleus $(\mathrm{N})$; uranyl acetatelead citrate; $\times 15517$; bar $=1 \mathrm{um}$

\section{Ultrastructure}

\section{Transmission electron microscopy}

A typical vegetative cell (Figs. 16 and 17) was irregular in outline with a thick electron-dense pellicle and a large nucleus having beaded and lobed chromatin similar to the mesokaryotic detail shown for Hematodinium sp. in blue crabs (Newman \& Johnson 1975), in Haplozoon axiothellae (Siebert \& West 1974) and in Syndinium globiformi (Hollande 1974). Condensed chromatin sometimes caused bulging of the nuclear membrane providing a 'knobby' nuclear profile. The nucleoplasm, composed of irregular light and dark areas, was abun- 

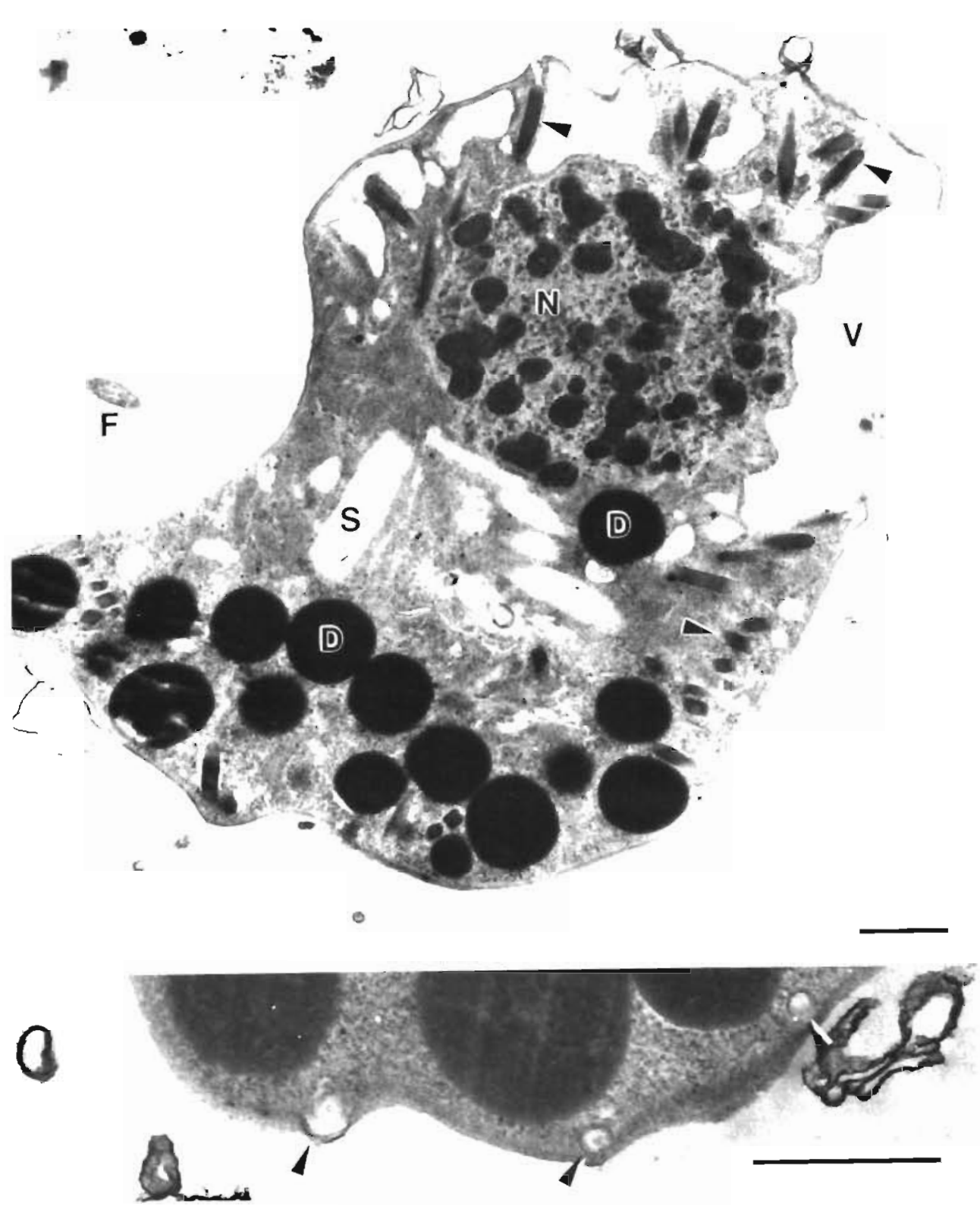

Fig. 19. Ultrastructure of the larger beaked dinospore from infected Tanner crab No. 4 after $10 \mathrm{~d}$ in hemolymph culture. Nucleus $(N)$, electron-dense bodies (D), trichocysts (arrows), flagellum (F), fibrillar polysaccharide-like material (S) associated with perinuclear space and endoplasmic reticulum and large empty vacuoles (V). Uranyl acetate-lead citrate. $\times 11900$, bar $=1 \mu \mathrm{m}$ Inset: Detail of similar dinospore showing pore-like structures (arrows) associated with pellicle. Uranyl acetate-lead citrate; $x$ $26000 ;$ bar $=1 \mu \mathrm{m}$

dantly interspersed among the chromatin while the nuclear membrane, though visible, was not well defined. Although almost certainly present, a distinct peripheral nucleolus was not observed and cytoplasmic invaginations were rare. The cell cytoplasm contained almost exclusively a homogeneous membrane-bound granular substance associated with large vacuoles containing a less dense lipid-like material. Some vacuoles were empty except for membranous debris (Fig. 18) similar to vacuoles shown for Solenodinium fallax (Hollande 1974).
Occasionally both vacuoles and granular inclusion bodies would occur in outward bulges of the pellicle. A few mitochondria and rough endoplasmic reticulum were the only other common eukaryotic cell organelles visible rarely within the thin strands of cytoplasm appressed against the cell wall or constricted between the homogeneous granular inclusions (Fig. 16). The cell theca did not have the typical dinoflagellate structure of vesicles containing plates. However, such detail may have been obscured by the extreme electron density of 
Figs. 20 \& 21. Flagellate dinospore. Fig. 20. Tangential section showing ultrastructure of smaller dinospore type from infected Tanner crab No. 9 collected immediately after sporulation; nuclear chromatin (C) densely interconnected and not beadedi few trichocysts (arrows) visible; uranyl acetate-lead citrate; $x$ $21000_{i}$ bar $=1 \mu \mathrm{m}$. Fig. 21. Similar section showing cytoplasmic concentric membrane structure (W) near flagellar groove (R) and fibrillar polysaccharide-like material. (S) associated with perinuclear space as in larger spore-type; uranyl acetate-lead citrate; $\times 22320$; bar $=1$
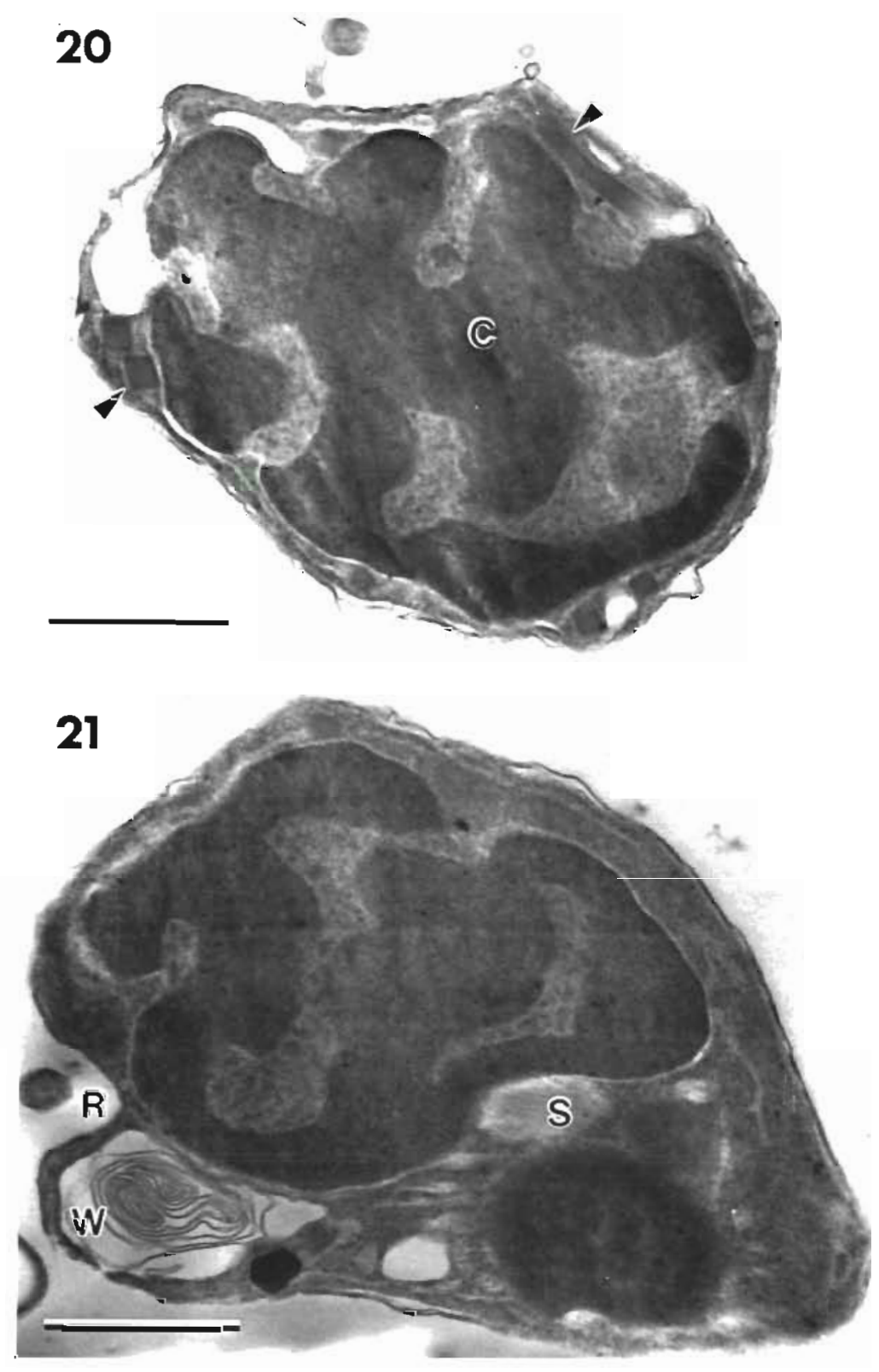
$\mu \mathrm{m}$

the pellicle in our material possibly resulting from a deposit or layer of polysaccharide-like material (Hollande 1974). Frequent breaks, separation of layers and irregular outward or inward folds were also features of the theca occasionally associated with bulging of the pellicle (Figs. 16 and 17). No cytoplasmic microtubules were apparent beneath the theca of vegetative stages, the lack of which is unusual among other parasitic dinoflagellates (Siebert \& West 1974). Trichocysts were also absent.

The larger dinospore from crab No. 4 had a less dense thinner pellicle than vegetative forms, with flagella showing a $9+2$ configuration and similar nuclear detail as in the vegetative stage above. Nucleoli again were not observed. Some spores contained a fibrillar substance within dilated perinuclear spaces and associated with the endoplasmic reticulum similar to the polysaccharide inclusions reported for spores of Syndinium globiformi (Hollande 1974). The large granular membrane-bound cytoplasmic inclusions in vegetative stages were absent but several electrondense bodies were abundant in most cells. The cytoplasm was also abundant and rough endoplasmic reticulum and mitochondria were more commonly observed along with numerous peripheral trichocysts having a rhomboidal transverse profile. A series of 


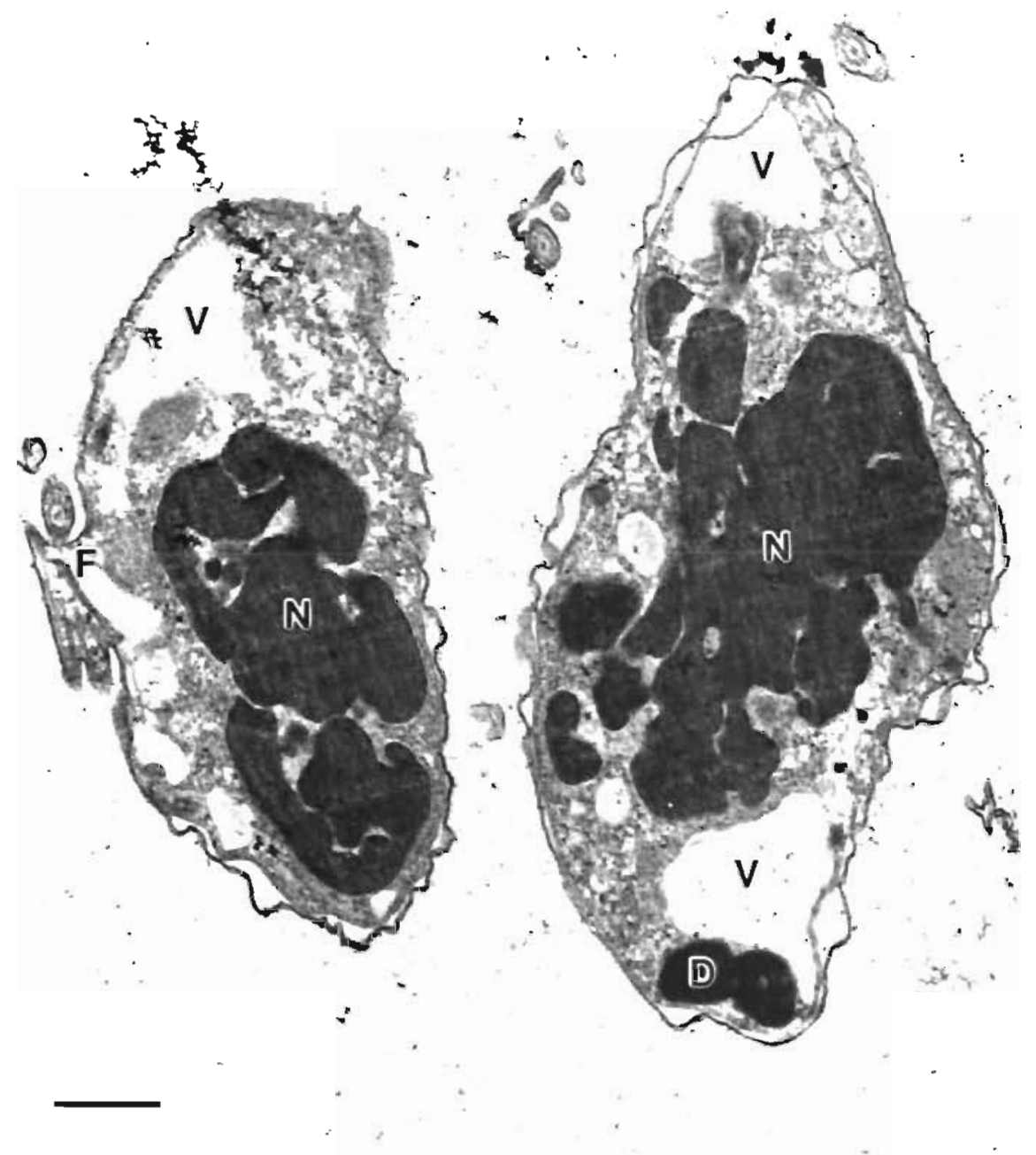

Fig. 22. Ultrastructure of smaller dinospore type after $23 \mathrm{~d}$ in saltwater culture. Longitudinal section. Cytoplasm more electron-lucent with large vacuoles (V) and few dense bodies (D); nucleus $(N)$ and flagellar attachment site $(\mathrm{F})$ for both circumferential and whiplash flagella. Uranyl acetate-lead citrate; $x$ $11390 ;$ bar $=1 \mu \mathrm{m}$. pore-like structures probably associated with trichocysts were visible at or just beneath the pellicle surface. Cytoplasmic vacuoles became more abundant as this spore type aged in laboratory culture (Fig. 19)

The smaller dinospores from crab No. 9 differed from the larger type by having a more dense nucleus with chromatin in large wide whorls surrounded by very little nucleoplasm. These spores had a larger nuclear to cytoplasmic ratio with less cytoplasmic volume containing much fewer electron dense bodies and trichocysts (Fig. 20). One sectioned spore contained a concentric membrane structure directly beneath the theca near the flagellar groove and a dilated perinuclear space filled with a similar fibrillar material as in the larger spore type (Fig. 21). As these dinospores aged in vitro the cytoplasm became more electron lucent with several large vacuoles (Fig. 22).

\section{Scanning electron microscopy}

Vegetative stages of the parasite were rounded to very irregular in shape and of varying sizes often attached to each other by intercellular bridges. The cell surface was randomly dispersed with depressions or pores of varying sizes. Many of these had a homogeneous material exuding from within appearing as smooth rounded droplets attached to each parasite cell exterior (Fig. 23). Elliptical to crescent-shaped crab hemocytes were abundant among the many vegetative parasite cells (Fig. 24).

The larger dinospores from crab No. 4 were ovate with rounded ends and had a 'warty' cell surface having a longitudinal keel and large folds (Fig. 25). The longest circumferential flagellum (15 um) was attached very near the distal anterior end within a small laterally located elongate cleft (Fig. 26). The shorter whiplash flagellum ( $5 \mu \mathrm{m})$ was attached underneath almost immediately behind the first but separated by a median ridge. It trailed within a deep longitudinal groove alongside a ventral keel, but did not extend beyond the spore body (Fig. 27). As this spore aged in vitro the ventral keel became more pro- 
Figs. $23 \& 24$. Dinoflagellate vegetative cells. Fig. 23. Scanning electron micrograph of vegetative stages (D) showing irregular thecal surface with pores and exuding droplets of unidentified material (arrows); gold palladium; $\times 4000$; bar $=10 \mu \mathrm{m}$. Fig. 24. Lower magnification of representative field of cells (D) showing single and multicellular forms exuding droplets and interspersed with some host granulocytes (arrows); gold palladium; $\times 1000 ;$ bar $=10 \mu \mathrm{m}$
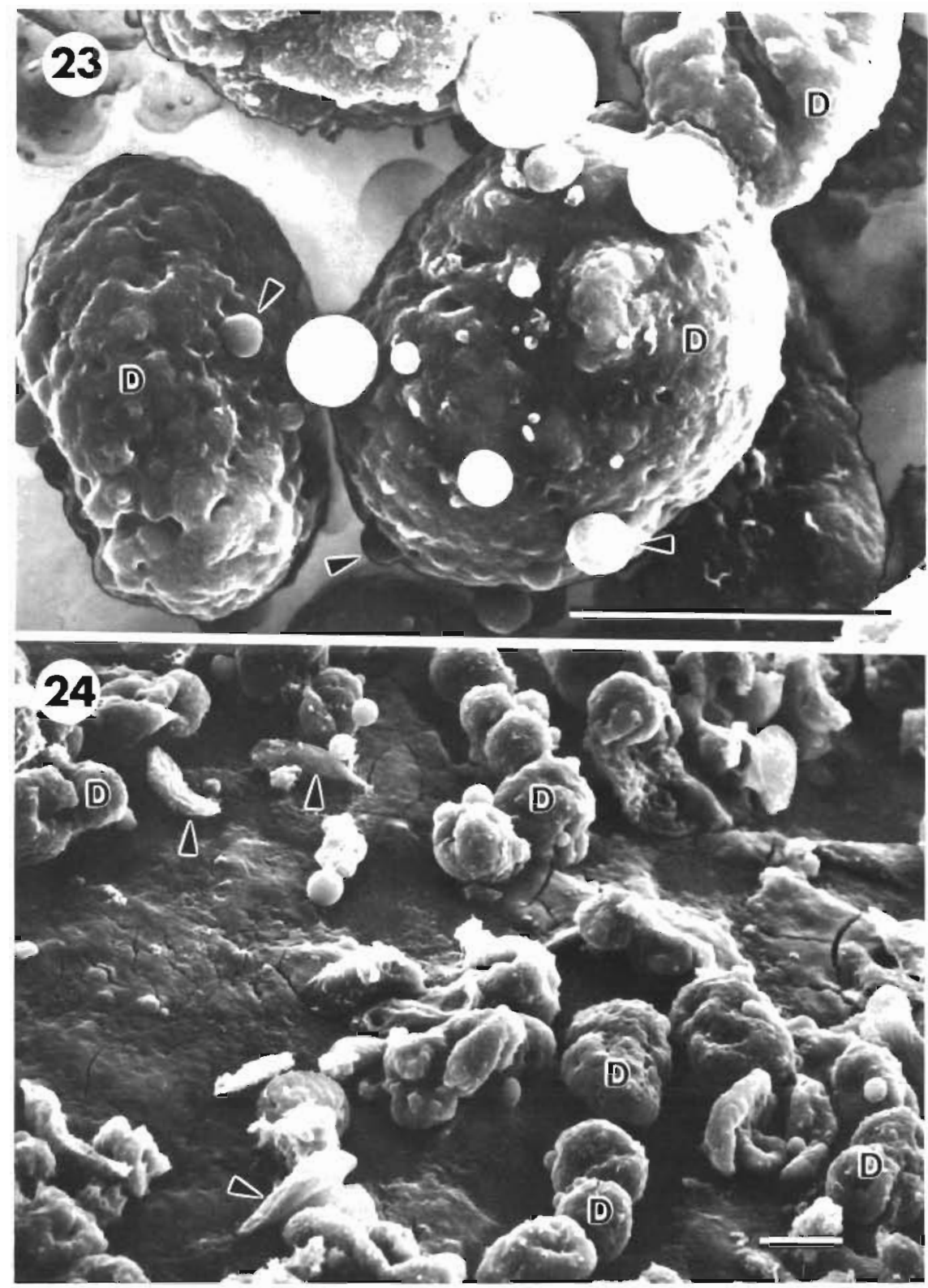

nounced and the anterior end of the spore became beaked (Fig. 27)

The smaller dinospore from crab No. 9 was quite different. The early spore body was elliptical, sharply pointed anteriorly and less so posteriorly with a smooth surface. A smaller ventral keel was also present (Fig. 28). The longer circumferential flagellum $(18 \mu \mathrm{m})$ attached further back on the body in a shallow depression. As in the larger spore type, the shorter whiplash flagellum $(5 \mu \mathrm{m})$ attached immediately behind the first but in a shallower longitudinal groove also separated by a median ridge (Fig. 29). The second flagellum extended well beyond the length of the spore. As this spore aged in vitro the anterior end became blunted and scalloped while the body developed a distinct corkscrew twist (Fig. 30).

\section{Disease transmission}

In the first experiment vegetative forms of the parasite were detected at 55 d post-inoculation (PI) in crab No. 8 receiving $1.1 \times 10^{6}$ of the cultured protozoan cells. At 69 d, crab No. 20 that received $2.2 \times 10^{5}$ cells from the same preparation also developed a detectable

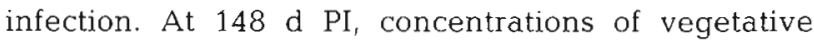
stages in both crabs were $2.73 \times 10^{6}$ and $1.21 \times 10^{6}$ $\mathrm{ml}^{-1}$ of hemolymph, respectively. These numbers indi- 

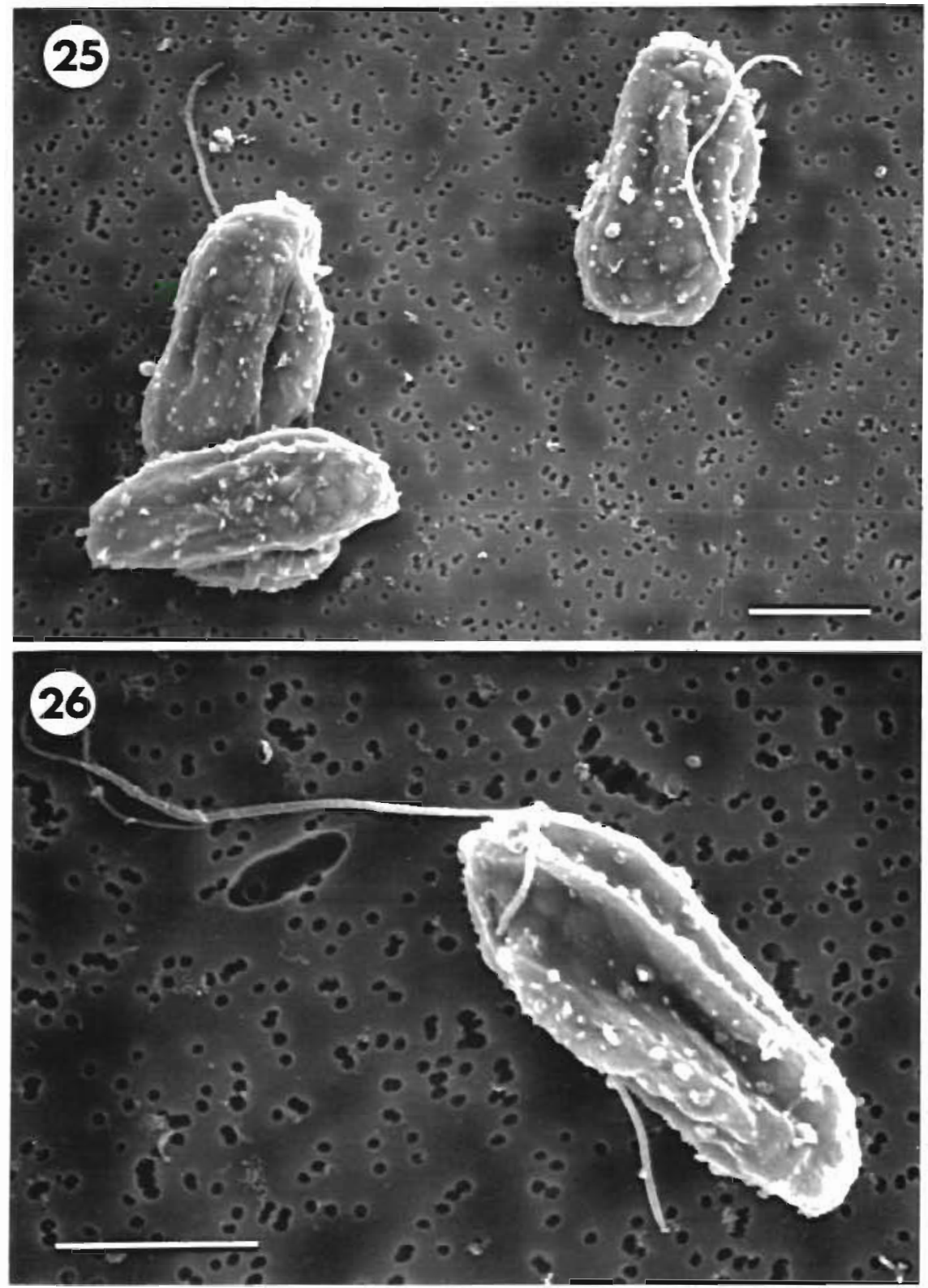

Figs. $25 \&$ 26. Dinospores. Fig. 25. Scanning electron micrograph of larger dinospore taken from infected Tanner crab No. 4 soon after sporulation; raised protuberances on pellicle, a lateral keel and flacella visible; gold palladium; $\times 3000$; bar $=5 \mu \mathrm{m}$. Fig. 26. Detail of large dinospore (similar to those in Fig. 25) showing attachment point of circumferential flagellum and portion of trailing whiplash flagellum (shrunken spore body is fixation artifact); gold palladium; $\times 5000$; bar $=5 \mu \mathrm{m}$ cated that the total concentration of organisms in each crab multiplied from inoculation doses by approximately 2 to $3 \log 10$ when considering total body hemolymph volumes. However, unexpectedly, both crabs inoculated with vegetative stages taken directly from crab No. 9 (in which vegetative stages sporulated 60 d later) remained uninfected after $214 \mathrm{~d}$ PI. At $63 \mathrm{~d}$ PI, a hemolymph smear from the crab receiving the larger dose of crab No. 9 vegetative stages demonstrated a single corkscrew-shaped dinospore. This discovery suggested that the inoculated vegetative stages had sporulated in this crab. Seawater temperatures for this duration were as indicated previously and all control crabs remained uninfected.
In the second experiment examining host species susceptibility vegetative stages of the parasite were detected at $83 \mathrm{~d}$ PI in 4 of the 5 surviving Tanner crabs receiving infected Tanner crab hemolymph. A 5th crab developed an infection at $97 \mathrm{~d}$ PI, while the 6th crab died early on in the experiment from undetermined causes. None of the king crabs inoculated with the dinoflagellate developed detectable infections $155 \mathrm{~d}$ PI. None of the sham inoculated crabs of either species developed infections, and only 1 control king crab was lost from cannibalism after molting. This experiment was initiated during late February when the seawater temperature was $4.5^{\circ} \mathrm{C}$. Respective average monthly seawater temperatures $\left({ }^{\circ} \mathrm{C}\right)$ during the experiment for 
Figs. $27 \& 28$. Dinospores. Fig. 27. Detail of 2 large dinospores from Tanner crab No. 4 after $10 \mathrm{~d}$ in hemolymph culture; attachment point of whiplash flagellum is within deep ventral groove almost immediately behind depression (arrow) for circumferential flagellum (missing); although almost obscured by particulate debris, a pronounced beak $(B)$ is apparent on the left spore; gold palladium; $\times 4000$; bar $=5 \mu \mathrm{m}$. Fig. 28. Smaller type dinospores from infected Tanner crab No. 9 taken soon after sporulation; a smaller ventral keel is present alongside the trailing whiplash flagellum, and the spore surface is smooth; gold palladium; $x$ $4000 ;$ bar $=5 \mu \mathrm{m}$
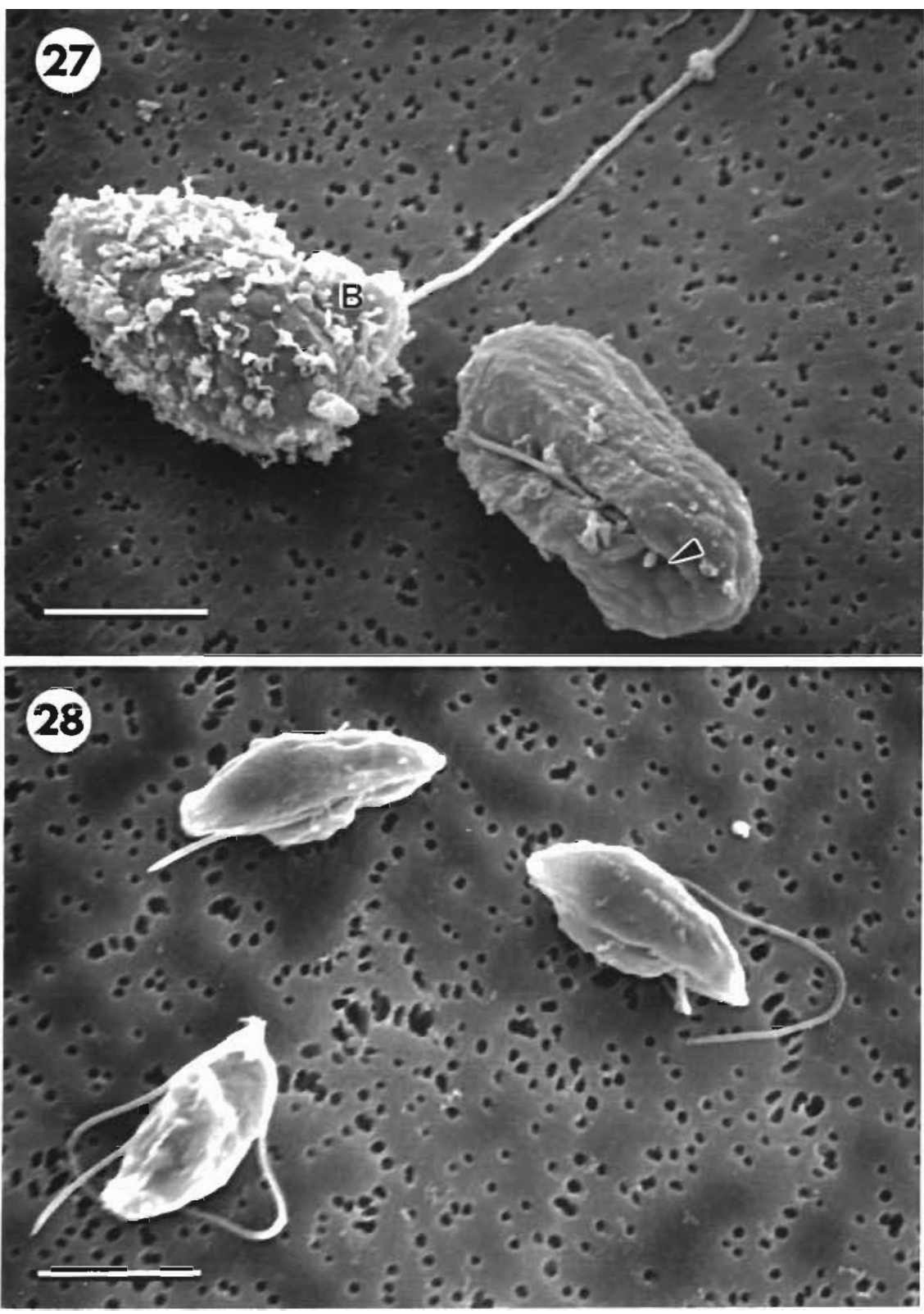

March, April, May, and June were; $4.4(\mathrm{n}=19), 5.1$ $(n=30), 5.6(n=27), 6.7(n=29)$.

\section{In vitro culture}

Within 2 to $3 \mathrm{~d}$ of seeding, dinoflagellate vegetative forms attached to the surfaces of the 2 up-ended flasks and subsequently formed incomplete monolayers within 12 to $15 \mathrm{~d}$ (Fig. 3). The antibiotic mixture added to hemolymph did not affect parasite cell survival and growth. Consequently, it was used thereafter in all cell preparations. By $17 \mathrm{~d}$, cells were detaching and loose within the supernatant fluid. The morphology of stained cells in suspended culture was identical to those in freshly drawn hemolymph from infected crabs. On Day 19 the flask with antibiotic was gently shaken to dislodge remaining cells which were centrifuged and resuspended in $15 \mathrm{ml}$ of fresh Tanner crab hemolymph for subculturing. Subsequently, second, third and fourth generation vegetative stage cell cultures were established with monolayers becoming confluent in about 15 to $18 \mathrm{~d}$. Such cell cultures were able to survive for months in undisturbed flasks. Occasionally, considerable cell clumping occurred rather than monolayers. These cell aggregates would periodically attach by pseudopodia then detach from the flask surface. As the cell clumps aged, occasional single cells 

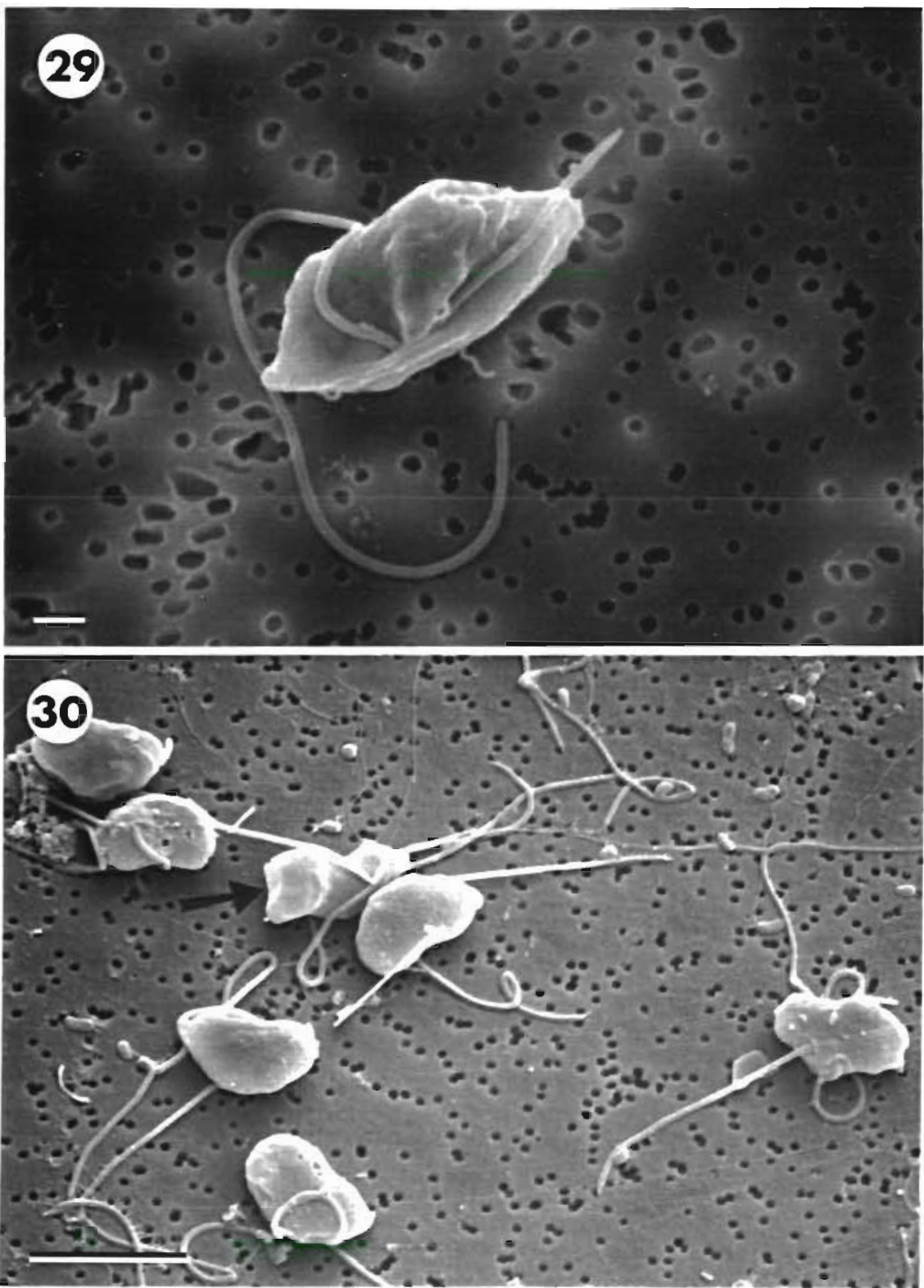

Figs. 29 \& 30. Dinospores. Fig. 29 Detail of flagellar attachment in small dinospore of same age as in Fig. 28; both flagella attach further back on spore body than in large spores, and whiplash flagellum trails beyond spore posterior; gold palladium; $\times$ 6000 i bar $=1 \mu \mathrm{m}$. Fig. 30. Small dinospores after $29 \overline{\mathrm{d}}$ in saltwater culture. One spore (arrow) has a distinct corkscrew twist and blunted scalloped anterior end; bacterial contamination of culture is evident; gold palladium; $\times 3800 ;$ bar $=5 \mu \mathrm{m}$ became hypertrophied with appressed nuclei suggesting a degenerative or senescent change. Considerable differences in size of attached single cells also became evident and correlated with the varying sizes observed in circulating hemolymph. Small cells were able to increase in size when observed for long periods in hemolymph cultures.

Suspended vegetative stages of the parasite were able to survive for at least $5 \mathrm{~d}$ in natural seawater $130 \%$ at $5{ }^{\circ} \mathrm{C}$ ) after which the preparation was destroyed by bacterial contamination. Dinospore stages from both crabs Nos. 4 and 9 were able to survive in sterile seawater for 73 and 52 d, respectively.

Cultures of the smaller No. 9 dinospores showed reduced activity $30 \mathrm{~d}$ after collection from the host crab and were also eventually overwhelmed by bacterial contamination that may have terminated their survival prematurely. Prespore stages from crab No. 9 collected $1 \mathrm{~d}$ prior to natural sporulation in the crab host were seeded into a culture flask of hemolymph. These cells readily attached in large clusters within 48 h of incubation at $6^{\circ} \mathrm{C}$. After $35 \mathrm{~d}$ in culture, these cells began sporulating into the dinospores typical of those collected from the donor crab host after natural sporulation. Sporulation in the culture flask was not simultaneous nor complete and proceeded slowly. Many prespore cell clusters did not sporulate and later died.

After $25 \mathrm{~d}$ in culture, some of the No. 4 large type 
dinospores in both hemolymph and saltwater developed into irregular shapes which no longer moved in a straight line but in a tight circular motion. In the hemolymph culture many of these cells eventually settled to the flask surface and attached by extended pseudopodia forming large clumps of non-motile cells. These attached forms were accompanied by chains of non-motile organisms loosely attached to the flask in a rosette-like pattern. In the saltwater culture only the rosette forms developed.

\section{Disease prevalence and distribution}

In 1985 bitter Tanner crabs were harvested from 3 areas in the northern end of Lynn Canal: Chilkoot, Chilkat, and Lutak Inlets (Fig. 31). During 1986, parasitized crabs were caught from several areas including: Upper Lynn Canal (excluding Berner's Bay) from Little Island northward; the Juneau area; Port Frederick and adjacent area 114-27 in Icy Strait; area 114-21 in Cross Sound; and area 111-20 in southern Stephens Passage (Fig. 31).

Commercial fishermen reported bitter Tanner crabs approaching a prevalence of $100 \%$ (Joe Donohue pers. comm.) in the narrow body of water between Sullivan Island and the mainland (Fig. 31). A pot survey conducted in this area $\left(58^{\circ} 56^{\prime}\right.$ north latitude and $135^{\circ} 21^{\prime}$ east longitude) by the ADF\&G (Alaska Dept of Fish and Game) found an overall disease prevalence of $95 \%$ among the $149 \mathrm{crabs}$ examined (Table 2). Hemolymph smears from 20 randomly chosen infected crabs showed previously described prespore stages in at least 1 individual ( $5 \%$ ). The intensity of infection in all crabs examined ranged from very light with 4 to 5 parasite cells per smear, to moderate with 50 to 100 cells per field, to severe with hundreds or solid fields of organisms and no host cells visible. Numerical values of 1 , 2-3, and 4-5 were assigned to hemolymph smears having light, moderate and severe infections, respectively. Using these very subjective values the average infection intensity from this field study was estimated as moderate (3). Since only 6 male and 2 female crabs were uninfected, there appeared to be no differences in parasite prevalence between the 2 sexes and among the size classes examined or with the depth at which gear was set. The largest male crabs were approximately 6 to $7 \mathrm{yr}$ old while the smallest female crabs were about 2 yr of age. Hemolymph smears from 5 red king crabs, 1 golden king crab Lithodes aequispina, and 1 blue king crab Paralithodes platypus incidentally caught in the gear did not have any detectable dinoflagellate forms.

Because of the high dinoflagellate prevalence the Sullivan Island area was closed to the commercial Tan-

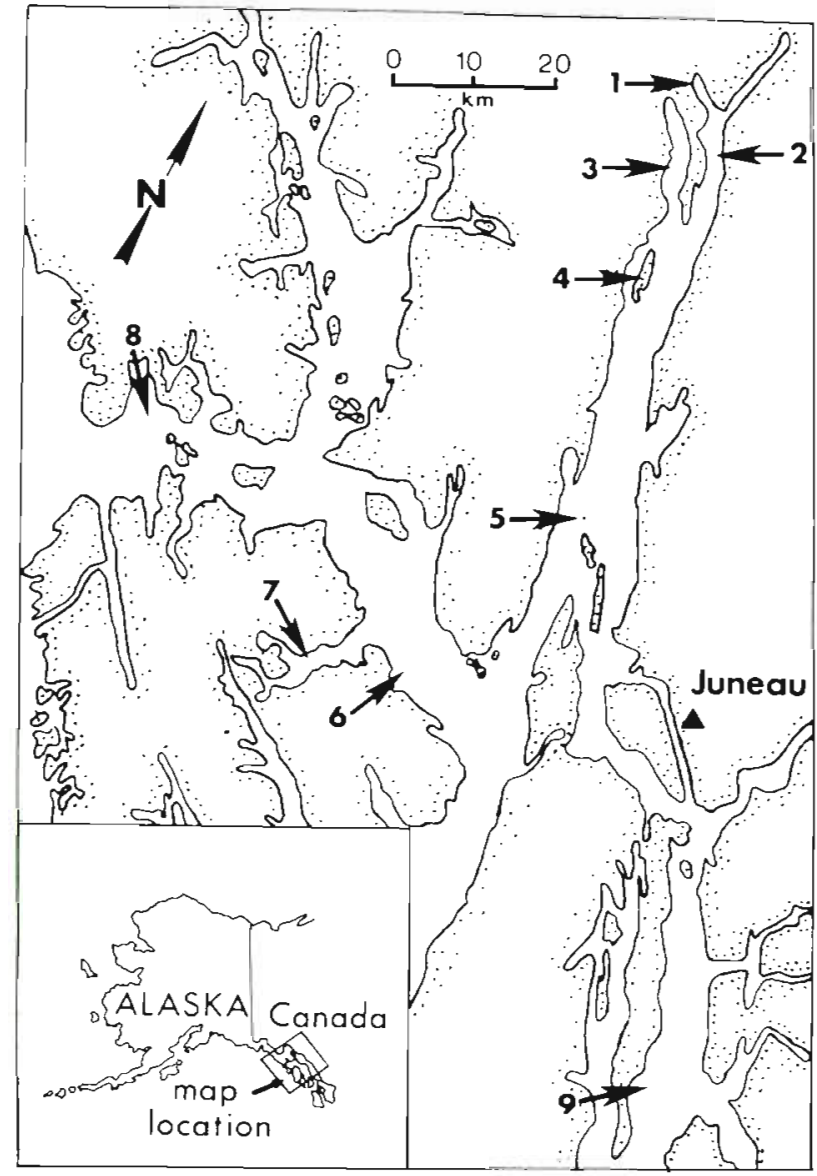

Fig. 31. Distribution of dinoflagellate infection in Tanner crabs harvested from northern southeast Alaska during 1985 and 1986. 1, Lutak Inlet; 2, Chilkoot Inlet; 3, Chilkat Inlet; 4 Sullivan Island; 5, Little Island (all preceeding areas in upper Lynn Canal); 6, area 114-27 in Icy Strait; 7, Port Frederick; 8 , area 114-21 in Cross Sound; 9, area 111-20 in southern Stephens Passage

Table 2. Chionoecetes bairdi. Prevalence of dinoflagellate parasitism in male and female Tanner crabs of different size classes near Sullivan Island, Alaska on 1 July 1986

\begin{tabular}{|ccc|}
\hline $\begin{array}{c}\text { Carapace } \\
\text { width }(\mathrm{mm})\end{array}$ & $\begin{array}{c}\% \text { Infected } \\
\text { males }\end{array}$ & $\begin{array}{c}\% \text { Infected } \\
\text { females }\end{array}$ \\
\hline $71-78$ & $(0)$ & $67(2 / 3)^{\circ}$ \\
$79-88$ & $100(2 / 2)$ & $92(12 / 13)$ \\
$89-98$ & $100(5 / 5)$ & $100(34 / 34)$ \\
$99-108$ & $100(4 / 4)$ & $100(4 / 4)$ \\
$109-118$ & $100(13 / 13)$ & $100(4 / 4)$ \\
$119-128$ & $82(9 / 11)$ & $100(1 / 1)$ \\
$129-138$ & $83(5 / 6)$ & $(0)$ \\
$139-148$ & $95(19 / 20)$ & $(0)$ \\
$149-158$ & $92(22 / 24)$ & $(0)$ \\
$159-163$ & $100(5 / 5)$ & $(0)$ \\
Total \% infected & $93(84 / 90)$ & $97(57 / 59)$ \\
Total \% new shell & 97 & 97 \\
& & \\
a No. infected/no. examined & \\
\hline
\end{tabular}


ner crab fishery in January and Februray of 1987. In March of that year the ADF\&G sampling effort within the same Sullivan Island grid area recovered only 50 Tanner crabs. Three of these were legal sized males, all of which were infected with the dinoflagellate disease. The overall disease prevalence in this sample of crabs was $37 \%$.

\section{DISCUSSION}

The gross milky appearance of hemolymph and tissues in bitter tasting Tanner crabs was caused by myriads of parasitic dinoflagellate organisms resembling Hematodinium sp. Much of the clinical disease in the host is caused by the non-motile vegetative uninucleate and plasmodial stages. Most of the vegetative parasite morphology, the gross clinical signs of disease and the histopathology of infected crabs were similar to reports of Hematodinium disease in blue crabs (Newman \& Johnson 1975). However, other features of this disease are distinctly different suggesting that the bitter crab agent is a new entity: vegetative forms of the organism were much larger than the average cell diameter of $8.1 \mathrm{\mu m}$ in the blue crab; no highly motile multinucleated vermiform bodies were observed; vegetative stages did not have trichocysts in the cytoplasm when examined by TEM (Newman \& Johnson 1975); diseased crabs have a bitter aftertaste when infected crab meats are cooked; sporulation does occur in the crab host producing one of two types of dinospores but not both.

In addition, this report is the first documentation of a decapod dinoflagellate disease in the Pacific Ocean and in Tanner crabs. The outcome of clinical disease in blue crabs is not documented, but mention is made that infected crabs die soon after capture and that diseased crabs, reaching a prevalence up to $30 \%$, cannot be found in late winter or early spring (Newman \& Johnson 1975). In the Tanner crab, the prevalence of infection can be much higher occurring during winter and spring while the course of the disease is chronic and prolonged over several weeks or months. Lower water temperatures and a larger crab host species may provide for longer development periods of this disease. The disease proved fatal to all infected crabs in the laboratory and may be capable of decimating natural Tanner crab populations. The latter possibility is supported by the ADF\&G sampling of $2 / 3$ fewer crabs from the Sullivan Island grid area in 1987 than in the previous year when $95 \%$ of the crabs were infected with the disease. Also, only $6 \%$ of the 1987 crabs were legal-sized males compared to $30 \%$ in 1986 . Commercial fishing could not have influenced the decline in population numbers because the area has been closed to harvest. The difference in sampling gear used in both years could possibly result in differences between total numbers of crabs collected but should not cause a significant discrepancy between relative numbers of legal-sized males.

Death of host Tanner crabs having bitter crab disease may result from two possible primary mechanisms; organ and/or respiratory dysfunction. Both are probably caused by the overwhelming numbers of replicating parasite cells which passively infiltrate and replace hemolymph elements and all vascularized tissues. The peculiar orange discoloration of epidermis and resulting pink carapace in infected crabs are probably caused by released carotenoid pigments from damaged epidermal cells. Crabs so affected are also not likely to survive the molting process. Overall host cell degeneration and necrosis may be caused by pressure atrophy, anoxia and/or toxic metabolites produced by the vast numbers of the organism. Stained hemolymph smears and SEM clearly demonstrated that vegetative stages produced considerable amounts of a substance in the form of minute droplets attached to parasite cell surfaces. Whether this material is toxic to host cells is not known. Those crabs surviving the vegetative phase of the disease die within 24 to $48 \mathrm{~h}$ after parasite sporulation that probably causes considerable mechanical disruption of tissues by the newly motile organisms. Another contributing factor to crab death may be secondary bacterial and ciliate protozoal infections in hosts already debilitated by the chronic vegetative phase of the dinoflagellate disease. The presence of these other agents in the hemolymph of 5 dead crabs could be argued as post-mortem artifact. However, the bacteremia observed in 2 crabs prior to death support the possibility of ante-mortem infection, at least by opportunistic bacteria.

Previous investigation regarding the cause of bitter flavor in Tanner crabs was done in 1985 by scientists within the National Marine Fisheries Service in Seattle. Their unpublished report, based on organoleptic and chemical tests of processed crab meats, concluded that the bitter flavor was due to the pre-molt physiological stage of the crabs (unpubl. data, memorandum 22 March 1985). This conclusion is not likely since most of the infected crabs we examined had new shells and were not approaching a pre-molt condition. We believe the bitter flavor of cooked meat from infected crabs results from either the dinoflagellate organism itself or a natural metabolite produced in the hemolymph by the parasite that permeates all tissues of the crab host. This product may be the same substance represented by the visible droplets attached to parasite cell surfaces. Whether the material within lipid-like inclusion bodies later forms the external droplets needs further study. However, chemical analysis of infected and 
uninfected crab hemolymph with parallel taste tests may support this speculation on the cause of bitter flavor.

The life history of Hematodinium sp. observed in decapod hosts has not been described. However, this present work has provided some factual information on which to propose a possible life cycle for the Tanner crab agent. Whether parasite development occurs within a yearly cycle or requires longer periods is still not resolved. Vegetative stages of the parasite divide in the host hemolymph over several months, eventually causing death in a large percentage of crabs. The vegetative stages in those few surviving crabs sporulate into motile dinospores causing crab death and putatively serve as the infectious stage or precursors to an infectious zygote stage produced by fusion of 2 different zoospore types representing male and female sexes. The morphological differences between the 2 spore types suggest the separate sex theory supported further by other work with pandalid embryo peridinienosis (Stickney 1978, Holmes et al. 1980, Hibbits \& Porter unpubl.) and syndinid parasites of Radiolarians (Hollande 1974). These investigators observed 2 different-sized spores for each parasite that were similar in some features to those in this report. However, fusion was also not evident when the 2 pandalid zoospore types were mixed. Nonetheless, separate-sexed dinospores might explain why 2 of our crabs receiving vegetative stages from a naturally infected crab never developed infections. The inoculated vegetative stages may have been sufficiently advanced in development that sporulation was imminent at approximately the same time as in the donor host crab as long as environmental conditions remained identical. Consequently, vegetative stages never had time enough to multiply to detectable levels in the 2 inoculated crabs. Also, resultant dinospore numbers were still too low for detection except for 1 spore in a single smear. If such spores were haploid, they would most likely be noninfectious and eventually eliminated by the host. The artificial environmental conditions of prolonged in vitro maintenance of the vegetative stages used in the 2 successfully infected crabs must have slowed or altered their normal development towards sporulation. Thus, the vegetative stage was perpetuated with subsequent multiplication to detectable levels. In both groups of crabs, the inoculation doses were roughly equal and should not have been variables. A predictable dose response was apparent regarding the lag period of detection between the higher and lower doses in the successfully infected crabs.

A second possibility is that both spore types in bitter crab disease represent 2 closely related but different dinoflagellate parasite species indistinguishable in the vegetative stage. The pandalid agent differed in that 2 types of vegetative stages were evident, each producing a different zoospore (Hibbits \& Porter unpubl.). However, these investigators also found that pandalid eggs were not infected when exposed to both types of live zoospores. We have not yet conducted transmission studies with the two zoospore types from bitter Tanner crab disease.

Some circumstantial evidence in both our pathogenesis and in vitro studies suggest that higher seawater temperatures may initiate parasite sporulation in the crab host if other environmental and physical factors remain optimum. This evidence included sporulation in naturally and certain experimentally infected crab hosts following rising seawater temperatures and retardation of imminent sporulation by in vitro placement of dividing prespore cells at a lower temperature. Admittedly, other artificial factors unavoidable in in vitro studies could have confounded the latter result. It may be likely that vegetative forms could persist for more than one seasonal cycle in those crabs surviving this phase of the disease in areas or depths where seawater temperatures remain low. In this case yearly natural mortalities from the disease may be much lower than we observed in the laboratory or which appeared to have occurred within the Sullivan Island study area.

Further epidemiological studies must be done to establish the route of transmission which is most likely by contact with either dinospores or a zygote produced by fusion of the 2 dinospore types. If dinospores are directly infectious, parasitism could also be established by ingestion of spores within infected crab tissues. Non-senescent morphological changes in spore development outside the host crab may have some significance in the competency of spores to either infect crabs directly or fuse with the opposite spore type to produce an infectious stage. Survival of both spore types for up to 2 to $3 \mathrm{mo}$ in seawater must certainly enhance the chance occurrence of host infection. Vegetative stages are passively infectious and can be transmitted to healthy Tanner crabs experimentally by parenteral injection. Histological observations showed that vegetative stages occur in the lumina of the bladder and digestive diverticula. Consequently, they are probably excreted with crab urine and feces. Although vegetative stages can survive for days in seawater it is unlikely they would be able to gain access to crab tissues or hemolymph by some natural process. Dinospores may also be released in the urine and feces while the host is still alive, but most likely are released en masse during tissue decomposition following crab death. Thus, Tanner crabs in the vegetative phase of the disease probably are not infectious for other crabs. Otherwise some of our control Tanner crabs which were previously confined for several days with natur- 
ally infected crabs in commercial live holds should have developed a detectable infection during their many months in captivity. The age or sex of host Tanner crabs do not seem to affect susceptibility to infection although further observations in younger age classes of Tanner crabs as well as other crab species are needed. It is encouraging to note that 7 king crabs from the severely affected Sullivan Island area did not appear to be infected and that the disease could not be transmitted to red king crabs in the laboratory.

The management and economical consequences of this disease for the Alaskan Tanner crab fishery are significant. Overfishing is probably the major cause for Tanner crab declines in certain areas but bitter crab disease cannot be ignored as a possible contributing factor. In addition to population reductions, the unmarketable bitter meats can result in considerable financial loss to processors or commercial crab fishermen. The only management of this disease in feral crab populations is in preventing parasite dissemination to unaffected Tanner crab areas. This approach could include the closure of severely affected areas to commercial crabbing and persistent culling of milky crabs on the fishing grounds before transport followed by a second culling at the processing facilities. Infected crabs from other areas should not be released into local waters to spread the disease. It would be significant to disease management if parasite development follows a yearly cycle with sporulation and new infections occurring in late summer or early fall. Newly infected crabs could be harvested in October through December before the disease has progressed far enough to cause a detectable bitter flavor. No culling of infected crabs would be necessary, all crabs would be marketable and the infected crabs could be utilized before mortalities occur from the disease. This alternative would also prevent the dissemination of the disease from release of unwanted bitter crabs in other waters.
Acknowledgements. We thank the following people for their important contributions to this report: Sitka Sounds Seafoods and Pelican Seafoods for catch and product data for the 1985 and 1986 Tanner crab seasons; the University of Alaska, Juneau School of Fisheries and Science and the Auke Bay Laboratory, NMFS for use of laboratory space and supplies; Dr Ralph Elston of Battelle Pacific Northwest Division in Sequim, Washington and $\mathrm{Mr} \mathrm{Al}$ Soeldner of Oregon State University for the quality TEM and SEM photomicrographs; Oliver Hofstad and Peter Philbin of the R/V 'Steller'; George Curtiss for technical assistance; Joe Donohue for catch information near Sullivan Island; and Dr Al Sparks for his valuable review of this manuscript.

\section{LITERATURE CITED}

Chatton, E., Poisson, R. (1931). Sut l'existence, dans le sāng des crabs, de peridiniens parasites Hematodinium perezi n. g., n sp. (Syndinidae). C. r. Séanc. Soc. Biol. 105: 553-557

Hollande, A. (1974). 'Etude comparee de la mitose Syndinienne et de celle des peridiniens libres et des hypermastigines infrastructure et cycle evolutif des syndinides parasites de Radiolaires. Protistologica 3: 413:451

Holmes, P. B., Mueller, G. J., Hauck, A. K. (1980). Observations and speculations on premature egg loss in Gulf of Alaska Pandalus borealis (pink shrimp). Soc. Invertebr. Pathol. XIII Ann. Meet. Seattle (abstract)

Johnson, P. T (1986). Parasites of benthic amphipods: dinoflagellate (Duboscquodinida: Syndinidae). Fish. Bull. U. S. 84: 605-615

MacLean, S. A., Ruddell, C. L. (1978). Three new crustacean hosts for the parasitic dinoflagellate Hematodinium perezi (Dinoflagellata: Syndinidae). J. Parasitol. 64: 158-160

Newman, N. W., Johnson, C. A. (1975). A disease of blue crabs (Callinectes sapidus) caused by a parasitic dinoflagellate, Hematodinium sp. J. Parasitol. 61: 554-557

Siebert, A. E., West, J. A. (1974). The fine structure of the parasitic dinoflagellate Haplozoon axiothellae. Protoplasma 81: 17-35

Stickney, A. P. (1978). A previously unreported peridinian parasite in the eggs of the northern shrimp, Pandalus borealis. J. Invertebr. Pathol. 32: 212-215 